\title{
Institutions and Institutional Logics in Construction Safety Management: the case of climatic heat stress
}

1. Andrea Yunyan Jia*, School of Built Environment, Curtin University, Australia

2. Steve Rowlinson, Department of Real Estate and Construction, the University of Hong Kong, Pokfulam, Hong Kong

3. Martin Loosemore, Faculty of Built Environment, University of New South Wales, Australia

4. Mengnan $\mathrm{Xu}$, Faculty of Urban Construction and Environment Engineering, Chongqing University, Chongqing, P. R. China

5. Baizhan Li, Faculty of Urban Construction and Environment Engineering, Chongqing University, Chongqing, P. R. China

6. Alistair Gibb, School of Civil and Building Engineering, Loughborough University, UK 


\title{
Institutions and Institutional Logics in Safety Management: The Case of Climatic Heat Stress
}

\begin{abstract}
We employed a Glaserian grounded theory approach to explore the gap between behavioural safety and its unsatisfactory outcomes. Data were collected through ethnographic studies on the practice of managing heat stress on thirty-six construction sites in Hong Kong and Chonqing in mainland China. Two core concepts, institutions and institutional logics, are generated and defined to explain why safety rules do not necessarily produce safety behaviours. At society level, we explicated two pairs of institutional logics: the religion logics (Confucianism vs. pragmatism) and the market logics (rational market vs. individualism). At project organisational level, two logics of processing safety in production are explicated: a protection logic in the Chongqing context and a production logic in the Hong Kong context. The concepts and sub-concepts are compared to existing business literature for clarification of scopes. Empirical findings of the study suggest safety intervention needs to redirect its focus from promoting safety alone to addressing the institutional logics of the entire organisation and its societal context practised by multiple levels of actors. We conclude that safety research would benefit from redirecting its focus of analysis from discourses, interviews or surveys to authenticated cases reconstructed through triangulation of actors' discourses at multiple levels of an organisation, third-party observation, physiological data and objective measurement of the work environment. Methodologically, this paper provides a detailed guidance for conducting grounded theory research with a focus of conceptualisation.
\end{abstract}

Keywords: grounded theory, climatic heat stress, institution, institutional logic, pragmatism, legitimacy

\section{Introduction}

The behavioural safety approach underpinning many safety programmes, campaigns and guidelines has been producing less safety behaviours than were hoped for. The safety-centred practices do not seem to be working as they are supposed to do (Mohammad and Hadikusumo 2015, Mullan et al. 2015). It is perhaps time to ask a more fundamental question: are we addressing the right problem? The weak link between safety initiatives and their desired behavioural outcomes can find its roots in the production system and the societal cultural contexts where various incentives, constraints, values and beliefs influence, seemingly irrelevant to safety but in effect, are premising individual decisions. Individuals make decisions on what goals they want to achieve and how they manage the perceived situations to achieve such goals, among which safety is one, but not the only one. Such a situational awareness leads us into a research inquiry of reconstructing the problem of safety management by developing a new theoretical perspective through a holistic understanding of its systemic context. The aim of this research is to develop a theoretical perspective from data of construction practice to explain safety-related behaviours influenced by multiple levels of systemic contexts. 
The empirical inquiry of our research was focused on the management of heat stress risks associated with working in hot weather that lead to heat illnesses or accidents (Chi et al. 2005). From a rational ergonomics perspective, heat stress is composed of six factors: temperature, humidity, solar radiant heat, wind speed, metabolic heat, and clothing effect (Parsons 2014). Metabolic heat generated by physical activities produces a significant amount of heat stress on the human body, which, in the construction work context, is directly related with workload, work pace and continuous work time (Rowlinson and Jia 2014). However the actual occurrence of heat illness is buffered by many other individual and organisational factors such as personal health, fatigue, hydration, psychological stress and adequacy of engineering control (c.f., Jia et al. 2016). For managing climatic heat risk on site, behavioural regulations and guidelines are readily available in many countries (cf. Rowlinson et al. 2014), which cover aspects of environmental thresholds linked with engineering controls and workrest regimes, hydration protocol and avoidance of dehydrating fluids, acclimatisation protocol and clothing. The aim of this paper is to explore how such guidelines, as formal safety rules, are processed on site and how the other peripheral factors come into play to influence the outcome of safety in hot environments. More specifically, through a grounded theory ethnographic approach, we introduce an institutional lens to examine the behaviour-regulating effect of explicit and implicit rules in safety and non-safety domains in a compatible platform. Meanwhile, the concept of institutional logic is mobilised to examine the internal consistency of such contextual influences.

\section{Precedents of grounded theories in construction safety management}

Construction management is regarded as an applied research field which is focused on solving practical problems and therefore, either does not need a theory at all, or has to take theories from 'mainstreams' such as psychology and management for empirical testing (e.g., Seymour et al. 1997). Borrowed theories rarely work well for the unique problems in construction practice. Attempts have also been made to develop theories grounded in empirical data from the field that work for construction practice (e.g., Loosemore 1998, Dainty et al. 2000). In the safety field, researchers have naturally turned to a grounded theory approach to understand causality in accidents. A good example is the development process of the Loughborough accident causality model, which came into being through an empirical investigation of one hundred non-fatal accidents as a research report to the UK Health and Safety Executive (Haslam et al. 2003). This was further systemised and conceptualised in Haslam et al. (2005), and progressed to more clarity in Gibb et al. (2006) through comparison to other accident theories, followed by its testing in different societal contexts (Cooke and Lingard 2011, Behm and Schneller 2013), and a consolidation of it (Gibb et al. 2014). Although the authors never claimed that they used a grounded theory approach, such a progressive process does feature a grounded theory approach.

The Loughborough model framed construction accident causal factors into immediate circumstances, shaping factors and originating influences (Table 1). The underlined assumption of the model is that an accident is caused by many factors in the whole systemic context, rather than a single error in the immediate circumstance. By this model, the risk of our study, climatic heat stress, is an attribute of the workplace located in the immediate circumstances of construction accident causality, which is formed 
by the shaping factors such as work scheduling, which is shaped by the originating influences at higher up the supply chain, such as economic climate.

Table 1. The Loughborough ConAC model (summarised from Haslam et al., 2003, 2005)

\begin{tabular}{|c|c|c|c|c|}
\hline \multirow{2}{*}{\multicolumn{2}{|c|}{ Immediate accident circumstances }} & \multirow{3}{*}{$\begin{array}{l}\text { Shaping factors } \\
\text { Site constraints; work } \\
\text { scheduling; house keeping }\end{array}$} & \multicolumn{2}{|c|}{ Originating influences } \\
\hline & & & \multirow{3}{*}{\begin{tabular}{l}
\multicolumn{1}{c}{ Proximal } \\
Permanent works \\
design; project \\
management; \\
construction \\
processes; health \\
\& safety culture; \\
risk management
\end{tabular}} & \multirow{3}{*}{$\begin{array}{l}\quad \text { Distal } \\
\text { Client } \\
\text { requirements; } \\
\text { economic } \\
\text { climate; } \\
\text { construction } \\
\text { education }\end{array}$} \\
\hline 1.Workplace & $\begin{array}{l}\text { Layout/space; } \\
\text { lighting/noise; } \\
\text { hot/cold/wet; local hazards }\end{array}$ & & & \\
\hline 2. Work team & $\begin{array}{l}\text { Actions; behavior; } \\
\text { capabilities; } \\
\text { communication }\end{array}$ & $\begin{array}{l}\text { Attitudes/motivations; } \\
\text { knowledge/skills; } \\
\text { supervision; health/fatigue }\end{array}$ & & \\
\hline 3. Material & \multirow{2}{*}{$\begin{array}{l}\text { Suitability; usability; } \\
\text { condition }\end{array}$} & \multirow{2}{*}{$\begin{array}{l}\text { Design specification; } \\
\text { supply/availability }\end{array}$} & & \\
\hline 4. Equipment & & & & \\
\hline
\end{tabular}

Built on the Loughborough model, Rowlinson and Jia (2015) identified institutional factors of construction accident causality at eight levels of systems to provide a finer granularity of contexts for the study of connectivity between site safety risks and the upper stream of the supply chain (Table 2). Through this framework, climatic heat stress is an institutional factor at the ecosystem level defined by site geography, local weather, regional climate and, on a historical scale, climate change. The value of Table 2 is that it brings together rational and normative rules within and outside of the safety domain at society, industry, organisation, project, team, job unit and individual levels into a conceptual structure that gives them compatibility in shaping human activities of adaptation towards a safe outcome. The framework generated from data of Hong Kong construction practice, serves as a preliminary theoretical model for the current study that provides guidance for theoretical sampling in a new round of Chongqing based field study for the generation of the new theoretical perspectives.

Table 2. Institutional factors identified at different stakeholders' system (Rowlinson and Jia 2015)

\begin{tabular}{|c|c|}
\hline $\begin{array}{l}\text { Levels of } \\
\text { systems }\end{array}$ & Institutional factors of construction accident causality \\
\hline Eco-system & Climate change | Regional climate | Local weather | Site geography \\
\hline Society & $\begin{array}{l}\text { Policy \& Legislation | Market | Pre-tertiary OHS education | Societal culture | The } \\
\text { sustainability conviction }\end{array}$ \\
\hline Industry & $\begin{array}{l}\text { Industry workload coordination | The sub-contracting practice | Client's contract } \\
\text { strategies | Training - Licensing system }\end{array}$ \\
\hline Organisation & Business model | Organisational culture | Training system | Production \& safety strategy \\
\hline Project & $\begin{array}{l}\text { Project leadership | Management infrastructure | Production strategy | Training system | } \\
\text { Risk management system | Financial reward system }\end{array}$ \\
\hline Team & Team leadership | Team culture | Team knowledge | Established practice \\
\hline Job unit & $\begin{array}{l}\text { Temporal \& spatial characteristics of the workplace | Psychosocial environment | } \\
\text { Financial incentives | Daily work patterns }\end{array}$ \\
\hline Individual & $\begin{array}{l}\text { Physiological conditions | Individual as agent of societal culture | Personal theory-in-use | } \\
\text { Personal repertoire of coping strategies }\end{array}$ \\
\hline
\end{tabular}

\section{METHODOLOGY}

A research community shares some common beliefs on how research should be approached, which makes a paradigm that separates one community from another and sometimes causes misunderstandings in cross-disciplinary communication (Lincoln and Guba 1985, Kuhn 2002 [1962], 
Fellows and Liu 2008). This includes the assumed epistemology and methodology and hence the legitimated process, methods, structures, language and outcomes of the research. The methodology used in this research falls out of the legitimated repertoire in the construction management research community, and therefore it is necessary to discuss the research paradigm before going into detailed report of the research methods. In the following sections we first give a brief illustration of the research paradigm authorised in the construction management research field, in contrast to which, we explain and set out the paradigm adopted in this research.

\section{Research as problem-solving or problem-framing}

The positivism paradigm assumes 'there are observable facts which can be observed and measured by an observer, who remains uninfluenced by the observation and measurement' (Fellows and Liu 2008: 17). Out of this epistemological tradition, the legitimate knowledge claims of a research are restricted to "facts" derived from scientific method, defended by observable evidences. The worth of research is evaluated by validity, reliability and objectivity (Kerlinger 1986). The construction management academic field in particular assumes research as a problem-solving activity. The legitimated research procedure, either qualitative or quantitative, is to start from a well-defined research problem (including selection of a theoretical framework from existing literature), followed by projecting a hypothesis as a provisional solution to the problem, collecting data around the variables in order to draw conclusion on either rejecting or accepting the null hypothesis (Fellows and Liu 2008). With rigor and objectivity, a good research is one that minimises the risk of making Type I error (rejecting the null hypothesis when it is true) and Type II error (accepting the null hypothesis when it is false).

This template of research, however, does not address a Type III error: that the highly focused, rigorously controlled and structurally executed research could be 'solving the wrong problem' (Raiffa 1968, Kirk and Miller 1986). Addressing this type of error takes dismissal of a predefined problem and a holistic consideration of the messiness of a situation, which, for a positivist paradigm, would be falling out of the criteria of rigor and objectivity. The strong problem-solving paradigm could also be attributed to the engineering origin of the construction management discipline (Langford and Hughes 2009). With the progressing of vertical integration in the industry, the construction management discipline is broadening its scope and hence its knowledge base (Murray and Langford 2004). In regard to the disciplines in the broad construction industry, the architecture discipline has been seeing problem-framing as a major activity in developing and applying design knowledge (Schön 1984, Kvan and Gao 2004). Schön (1983) describes design process as a reflective conversation with the situation through which the architect iteratively formulates a design problem to give some order to a messy situation. He draws from Dewey (1938) to argue that this iterative process is how we construct knowledge to address issues in the real world, in which problem-framing is an indispensable stage (Schön 1984, Schön 1987, Schön 1988). It is noteworthy that the formulation of a problem, here, is not an activity of selecting from existing frameworks, but a direct interaction with the 'problematised' situation; and it takes the researcher's personal involvement to make the conversation 'reflective'. The underlined epistemological paradigm is attributed to social constructivism (Piaget 1955, Berger and Luckmann 1966, Goodman 1978), which comes under the umbrella of interpretivism that assumes "reality is constructed by the persons (and things) involved" (Fellows and Liu 2008: 18). 


\section{The grounded theory approach}

The theory is generated from data of heat stress management practice on construction sites in two societies, Chongqing Municipality in mainland China and the Hong Kong Special Administrative Region, using a grounded theory ethnographic approach based on a social constructivist epistemology. Grounded theory is an inductive approach of generating theory that is grounded in data and usable in practice, featured by theoretical sampling and constant comparison. The methodology was initially formulated by Glaser and Strauss (1967), and detailed by Glaser (1978), as a result of systemization and justification of their methods used in a sociological research. In the 1990s there was a split in terms of epistemology between the two founders, where Strauss adapted grounded theory into a positivist paradigm to produce a structured guide (Strauss and Corbin 1990), which proved popular among the 'main stream' readers and was followed by many methodology books; while Glaser (1992) went on to reject the positivist paradigm to "keep genuine orthodox grounded theory on track” (Glaser 2001: 3). Although Glaser rejected any labelling of a particular epistemological standpoint, the essential character of grounded theory approach he described, (i.e., researcher's personal involvement in the data interpretation and conceptualisation process sensitised by his or her personal knowledge (Glaser 1978, 1992), suggests a presupposition that reality is socially constructed between the researcher and the facts (Glaser 2001, 2003), which generally subscribes to the social constructivism epistemology. From the orthodox of construction management methodology, the Glaserian approach was questioned for its rigor (Fellows 2009). Acknowledging a social constructivism epistemological stance, we would argue that the rigor of grounded theory research lies in its systemisation and transparency of the process, rigorous verification of data through extensive fieldwork and triangulation of multiple sources. Strauss and Corbin's (1990) conformity to the objectivity criterion has inevitably compromised some fundamental characteristics of the grounded theory approach, such as reflexivity.

Grounded theory as a paradigm rejects preconceived research problems or theoretical frameworks prior to data collection required by the positivist paradigm. Instead, the research inquiry starts from a broad area of interest with 'no problem'. The researcher "moves in with the abstract wonderment of what is going on that is an issue and how it is handled. Or what is the core process that continually resolves the main concern of the subjects" (Glaser 1992: 22). That is, to allow the data to determine what is the 'true problem' in the area rather than to let a well-defined research problem predetermine what to look for (and see) in the field. Such a grounded process is an analogy to practitioners' reflection-in-action process of generating personal knowledge, during which the problem is defined and redefined through a continuous conversation with the situation until it points to a best solution that works for reality (Schön 1983). Thus the advantage of a grounded theory approach lies in its acceptance of the messiness of problems in reality and its legitimation of a problem framing stage as an important part of the research procedure. Throughout the coding process, the analyst makes her judgement of categorising by constant comparison and going back to theoretical sampling for more data if necessary. This iterative process includes the research activities of triangulation, hypothesizing, verification and falsification as articulated by Strauss and Corbin (1990). However, it is important to note that under a grounded theory approach these actions are processed as an evolving process of 
"checking, modification and densification" (Glaser 1992). Figure 1 illustrates the process of a grounded theory research approach.

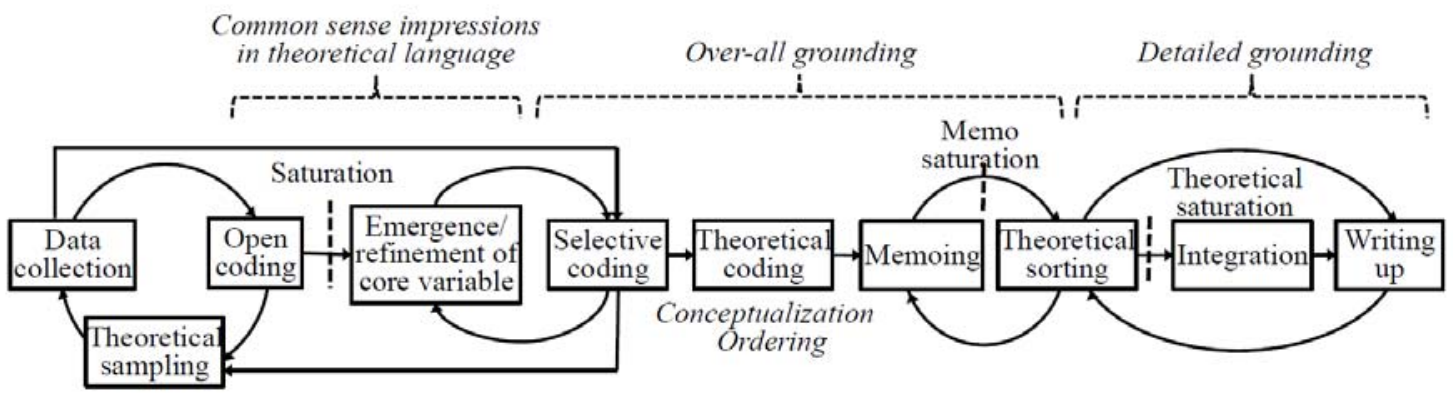

Figure 1. The iterative process of the grounded theory approach (adapted from Glaser 1978)

\section{Theoretical sensitivity}

Grounded theory is generated from data through researcher's theoretical sensitivity. Theoretical sensitivity refers to the researcher's background knowledge, understanding and skills, which sensitise him or her to address certain kinds of questions, to generate categories and properties, to integrate hypotheses, and to relate the generated theory to the data. Rather than holding a well-structured framework as 'law' for the research investigation, grounded theory researchers keep a personal repertoire of theories and concepts beneath the research inquiry (Glaser 1992). Such a personal repertoire of knowledge, processed at a preconscious level, forms guidelines for the researcher to formulate questions, leading to purposeful data collection, from which to generate new concepts. The key difference between using theoretical sensitivity and a preconceived set of theoretical hypotheses lies in the degree of formality (Glaser 1992), and therefore its power, that limits the possibilities of reformulation of the problem and discovery of the unexpected. Throughout the coding process, the researcher is not aiming to verify or falsify a preconceived 'truth' using data as evidence, but rather, he or she assumes a challenging, but more open-minded role seeking to discovering to switch or adjust the personal frame of reference whenever the data tell a different story.

\section{Theoretical sampling}

Theoretical sampling is an essential characteristic of a grounded theory approach, where the collection of new data is iteratively guided by the emerging theory. In most cases, theoretical sampling achieves adequacy at a much smaller sample size than that needed in random sampling for statistical validity. The underlined rationale is that grounded theory research is not destined to achieve descriptive accuracy in a population but to identify new categories, properties or patterns of relationships through maximising diversity in the data. Theoretical sampling stops at a stage of 'saturation' when new data do not generate more categories and the theory is approaching stable integration (Glaser and Strauss 1967).

\section{Research procedure}

We initially followed guidance from Strauss and Corbin (1990) for conducting this study. As the research went deeper into analysis and conceptualisation stage, more meaningful guidance was taken from Glaser's works (Glaser 1978, 1992, 2001, 2003) that explain in-depth the iterative process of 
theory generation. We started from fieldwork with a general interest in understanding the experiences and coping strategies of heat stress among construction workers and what was going on in the context of construction site management to ensure workers' safety in hot weather. The researchers' attention was focused on a central interest of safety in heat and a purpose of theory generation. The broad safety management and regulative contexts were also explored for understanding the peripheral contributing factors in construction safety management. A core category, institutions, became clear with the data analysis process, resulting in a grounded theory on construction accident causality (c.f. Rowlinson and Jia 2015, summarised in Table 2). The writing process generated a new area of interest: is this grounded theory culture-bounded, and, what would it be in a different social cultural context? This triggered a new round of theoretical sampling for researchers venturing into the field in Chongqing. The new round of data analysis came up with a shifted core concept: institutional logic. Literature on institutional logic was then searched and compared for two purposes: as data, and as knowledge that adds to the researchers' theoretical sensitivity for conceptualisation of the data.

To gain authentic insights into the practices on construction site, an ethnographic approach was used as a major data collection strategy (Tutt et al. 2013a). Ethnography requires the researcher to consider the whole ecology of organisations in the role of an empathetic insider (Griffin and BengrY-Howell 2007, Pink et al. 2010). However, it is not the purpose of our study to produce an accurate, vivid, detailed ethnography of the field (Czaniawska 2003, Marshall and Bresnen 2013). Rather, the grounded theory research employed ethnographic method as a data collection technique where the holistic assimilation of information on site was to figure out the authentic account of what was going on in the research scene, prepared as living stones for conceptualisation and theory generation. Thus the field data collection was done through an intensive engagement on each site for a short period of time; this may be classified as 'rapid ethnography' (Loosemore et al. 2015).

\section{Data collection protocols}

Data from the Hong Kong study was collected from 34 construction sites, 253 workers (from 37 trades) and 95 managers (of 34 positions) during the summers of 2010 and 2011. As the Hong Kong study was part of a research mission for producing construction-specific heat stress management guidelines commissioned by Hong Kong Construction Industry Council, the sample size was a result of negotiation with the committee members whose knowledge background set their expectation of sample size as defined by a questionnaire survey methods. Guided by the developed theoretical perspective, more focused theoretical sampling and data collection were conducted in the Chongqing study. The Chongqing sample came from two construction sites, six workers (from three trades) and nine managers. Details of the samples can be seen in Appendix 1.

We developed a two-day data collection protocol in the Hong Kong study where the research team spent two full working days on each site, meeting workers in a site office at a pre-work session and an after-work session, and observing activities on site during the day. Each day started with simple measurement of body weight, height, temperature and blood pressure, and a quick discussion with the workers on their sleep quality and leisure activities. After the meeting workers left for their daily work wearing a heart rate monitor while researchers went around the site conducting observations and 
semi-structured interviews with managers. At the end of the day workers had repeat measurements and a further discussion with the researchers regarding their work activities over the day. A semistructured interview on the heat illness experiences, heat stress prevention measures and the related project, organisational, and industrial environment was conducted at the end of the second day. The data collection of the Chongqing study was slightly different, where the informal site management structure and culture made it easier for researchers to build trust with the participants. Thus the data collection protocol was compacted into one day and found to be effective. Details of the two research protocols are shown in Table 3. They are further justified and described in the following paragraphs.

Table 3. Data collection protocols

\begin{tabular}{|c|c|c|c|c|}
\hline & & Prior-work session & Day time & After-work session \\
\hline \multirow[t]{2}{*}{$\begin{array}{l}\text { Two-day } \\
\text { protocol } \\
\text { (HK } \\
\text { study) }\end{array}$} & Day 1 & $\begin{array}{l}\text { Introduction; } \\
\text { Demographic data; } \\
\text { Personal baseline data }\end{array}$ & $\begin{array}{l}\text { Continuous data } \\
\text { recording at workplace; } \\
\text { Site observation }\end{array}$ & $\begin{array}{l}\text { Informal interviews } \\
\text { (workers); } \\
\text { Personal baseline data; } \\
\text { Administer questionnaire }\end{array}$ \\
\hline & Day 2 & $\begin{array}{l}\text { Collect completed } \\
\text { questionnaires; } \\
\text { Personal baseline data }\end{array}$ & $\begin{array}{l}\text { Continuous recording at } \\
\text { workplace; } \\
\text { Site observation; } \\
\text { Interview with managers }\end{array}$ & $\begin{array}{l}\text { Semi-structured interviews } \\
\text { with workers }\end{array}$ \\
\hline \multicolumn{2}{|c|}{$\begin{array}{l}\text { One-day protocol } \\
\text { (CQ study) }\end{array}$} & $\begin{array}{l}\text { Introduction; } \\
\text { Demographic data; } \\
\text { Personal baseline data; } \\
\text { administration of } \\
\text { questionnaires (workers) }\end{array}$ & $\begin{array}{l}\text { Continuous data } \\
\text { recording at workplace; } \\
\text { site observation; } \\
\text { interview with managers }\end{array}$ & $\begin{array}{l}\text { Semi-structured interview } \\
\text { with workers; personal } \\
\text { baseline data }\end{array}$ \\
\hline
\end{tabular}

A major constraint on the site-based study on heat stress was the length of summer season that lasts for four months in both Hong Kong and Chongqing. A further constraint for ethnographical study on construction sites is the "internally varied temporalities" (Marshall and Bresnen 2013: 112) of construction projects stretched by the in-and-out of trades, subcontractors and individual workers. Indeed, there were individual workers who left their jobs and teams finished their trades and left site in the middle of our study.

Apart from the time constraint, common challenges for ethnographic study in construction site are site access and trust building with the hierarchically organised research participants of more or less conflicting interests. Typically in Hong Kong, for both safety and commercial concerns, access to construction sites had to be endorsed top-down by senior management to site managers. Therefore the research team first approached senior management of clients' or contractors' organisations through the second authors' personal network and the board members of the taskforce of Construction Industry Council. The senior managers nominated construction sites and assigned managers to arrange site access for the researchers. These 'gatekeepers', however, were not part of the workers' community. Whilst indispensable, this path of site access posed potential restriction or distortion to the information to be collected from workers, either through concerns of confidentiality or a social desirability to please their supervisors (Argyris 1952). Therefore having entered the site, the researchers endeavoured to build rapport and personal trust with the workers to reduce the 'top-down' effect. The activities of health check and daily engagement endorsed the researchers a nursing role, independent from the site managers, thus effectively facilitated a quick trust building with the 
workers. For an authentic account of such an organisational context, the ethnographers strived to understand workers' perspectives and concerns while engaging the management team in a joint mission of improving team morale and site conditions and thus, their job performance. An experience gained from our site study is that researchers must be diligently creating win-win situations whenever a new group joins the scene, with vigilance and sensitivity in boundaries, roles and varied extents of influence in different project organisations. More details of the data collection process as well as the interrelationship among the risk factors of heat stress can be seen in Jia et al (2016).

\section{Data analysis}

Initial data treatment

Sources of raw data included field notes of on-site observation and interviews, meeting minutes and email communications with major stakeholders in the Safety Committee of Construction Industry Council, questionnaire and interviews from industry workshops. Data on formal documents included reports of local climate from Bureau of Meteorology's websites, national and regional guidelines related to heat stress management and relevant media reports. The qualitative data were added by quantitative data including workers' heart rate record and workplace heat stress record recorded at one-minute interval of the full working days during field study. These were initially analysed with the Predicted Heat Strain model (Malchaire et al. 2001) to calculate the difference between the maximum allowable continuous working time and the work shift being practised on site. Workers' demographic and personal health data were treated as control variables in the analysis.

\section{Authentication of cases}

The multiple sources of data after initial treatment were triangulated and verified to reconstruct an authentic scenes of the work activities situated in the working environment. False information was dropped after the verification. The verified data were sorted into cases at individual and project levels for theory generation (see Appendix 2 for an example of the case). Following are three examples of the authentication process.

Example 1: A safety manager stated that they had provided drinking water on site, while workers stated they were lack of drinking water provision on site. In observation, researchers found that the site did have a drinking water station but it was placed in a non-accessible location and therefore was not actually in use. In this case, the manager's statement was excluded from the data.

Example 2: A worker said that he had a heat illness incident at 11 a.m. in a study day. He stated the reason of the incident was because he "had such a heavy workload in such a hot weather". However, the result of heat stress analysis indicated incident happened at a mild level of temperature and humidity. By observation, the worker was working indoor and was not exposed to direct sunlight. His heart rate record indicated that he was working in light workload only. On the other hand, his personal health information recorded in the pre-work study session showed that he was 64 years old, with high blood pressure and a very poor 
physical fitness. Through triangulation, the case was interpreted as an ageing case. The worker's self-statement of "heavy workload in a hot weather" was dropped.

Example 3: A manager on a Hong Kong site mentioned there was a lack of coordination in the overall amount of work in the construction industry, which made them very difficult to find the right employees. When government commenced several large infrastructure projects at once to boost economy, there was a serious shortage of labour in the market. At the end of the cycle when most projects were completed, managers and workers were redundant, looking for jobs in other occupations. These messages from an interview were then triangulated with a recent report by the Construction Association, a discussion paper of the Legislative Council, and a media report in a major local newspaper (South China Morning Post) to make a case that is attributed to the 'markets as institutions' category below.

Theory generation

Following steps suggested by Glaser (1992, 2005), the data analysis went through open coding, selective coding, theoretical coding, memoing, sorting and integration. Open coding involved initial conceptualisation of data, during which the analyst labelled each incident with categories and properties. When a core category emerged (e.g. institution), the analysis moved to selective coding, which meant only the data relevant to the core variable were selected (or collected) for coding. When the categories and properties came to saturation, the analysis moved to theoretical coding, that is, to conceptualise the relationship among the categories to address the main concern, safety in heat. This was guided by the coding family of Six C's as suggested by Glaser (1978): cause, consequence, condition, covariance, context, and contingent (Figure 2). Memos on emerging ideas about codes and their relationships were noted down from the start of the fieldwork in constant discussion and cross checking with senior and junior members of the research team. On completion of theoretical coding, the analysis moved to sorting, that is, to align the memos with the emerged theory. The researcher then wrote up the theory while integrating the categories. In the process of sorting and integration, the emerged theory is checked in details to be further grounded in the data (see Appendix 3 for coding examples).

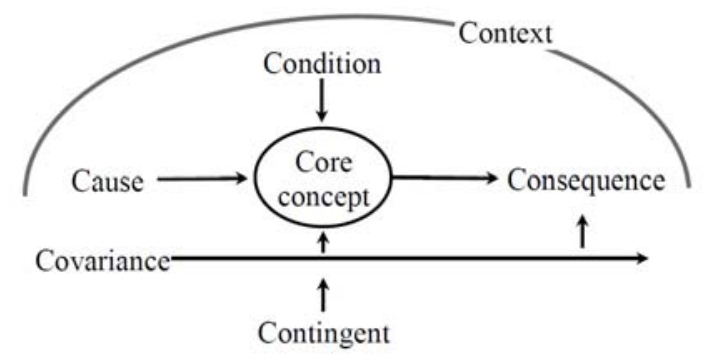

Figure 2. The 'six Cs’ coding family (adapted from Glaser 1978: 74) 


\section{FINDINGS: THE EMERGED THEORY}

The two core concepts emerged from the data were institution and institutional logic. Institutions are defined as the nominal and rational premises of decisions, including externally imposed or selfenforcing laws, structures, rules, regulations, cultures, norms, routines, cognitive frames and established practices that explicitly or implicitly govern individual and organisational decisions and actions. Institutional logic is defined as the central values constituting the core identity of individual or organisational actors, which direct attention and endorse meaning, legitimacy, justification and consistency to the practices and discourses of the actors. The explicit and implicit institutions are often contradicting each other; and the sum of them constitutes the rational and normative decisionmaking infrastructure for an actor (either an individual or an organization). Institutional logic determines what institutions are perceived to be available, which of them are activated in what meaning for what purpose. While contingencies seem to have a deterministic effect on behaviours, such effect is mediated by actor's autonomous decisions of conforming to or complying with some institutions outside of the immediate contingency. The concept of institutional logic explains how these decisions are made, addressing the issues that actors selectively perceive the information available to them; they selectively process the perceived information; they formulate problems that bound their repertoire of solutions; and they consistently apt to certain kind of solutions over others. The selectivity of intentions, attentions and preferences is driven and endorsed by a central logic, the central logic of the actor's theory-in-use (instead of their espoused theory).

Whilst existing literature tends not to distinguish between the two concepts of institution and institutional logic, the emerged theory out this set of data suggests a clear distinction between them. A plain illustration of the distinction can be drawn from the text of the Scripture: The Old Testament gives numerous behavioural rules and values (institutions); while the New Testament makes clear that the implementation of these institutions are guided by two contrasting central logics: a legalism logic and a logic of charity. The former featured the learned society who tended to interpret the institutions as performance measurement and to practise behavioural compliance as a means of claiming social prestige. The latter was practised by Jesus who interpreted and practised the institutions as guidelines of loving people. Manifested in actions, the two different kinds of actors made opposite decisions in response to the same contingency, drawing from different institutions underlined by their respective institutional logics. In one occasion, on how to treat the people of indecent occupations, the social elites draw from the institution of holiness (e.g. Leviticus 20) to exclude these people; while Jesus applied the institution of mercifulness (e.g. Leviticus 23:22) to dine with them and did not mind to be despised as one of them (see Matthew 9). In another occasion, Jesus ignored the institution of "no work should be done on the Sabbath day" (see Exodus 20: 8-11) to heal the sick; while the law administrator judged the healing action as non-compliance, correctly, out of his legalism logic (see Luke 13). Institutional logic is tacitly influenced by the actors' historical contexts and is projected to the actor's future actions.

In the following sessions the findings are reported in this sequence. First, we explain the multiple institutions explicated from the field data, followed by a comparison of institutional interventions on 
heat stress management and their invoked responses from individual workers and project organisations in the two societal contexts. We then explain the institutional logics explicated at society-level (i.e. a Confucianism logic and a pragmatism logic in the religion logic category and a rational market logic and an individualism logic in the market logic category), followed by the project organisational level logics of processing safety in production (a protection logic and a production logic). We then proceed to discuss the interactions between institutional logics, institutional environments and actors' intentions, attentions and preferences with two cases.

\section{Institutions}

\section{Temporal and spatial institutions}

Institutions are created when people formally and informally organise their time and space into regular patterns that impact on their activities. The Hong Kong workers had a clear separation between work and life domains, resulting in a two to three hours daily travelling time between site and home. While the Chongqing migrant workers had a mixed space for work and life, which minimised time for daily travelling and made it possible for a nap after lunch, thus made them safer in heat. This will be further discussed in the following sections.

\section{Regional climate}

If we accept that human activities play a role in the change of climate, then the eco-system can be seen as constructed between the sum of human activities and nature. Climate thus forms an institution that constrains or drives human activities. In the case of heat stress management in construction, regional climate forms an institution at the ecosystem level that, though rarely a factor of consideration in project planning, largely shapes the yearly cycle of work activities and their safety outcomes. Seasonal variance was observed in the construction accident rate where a peak appeared in summer (Helander 1980). Specifically, environmental heat stress is composed of four factors: temperature, humidity, solar radiant heat, and wind speed (Parsons 2014). The characteristics of regional climate determine the patterns of environmental heat risks, leading to difference in effectiveness of interventions. In this study, both Hong Kong and Chongqing are both in the subtropical climate zone with summer ranges from May to August. However, Hong Kong has an oceanic climate while Chongqing's climate is inland, which means the summer of Hong Kong is more humid, with higher wind speed, while Chongqing has a higher range of air temperature but less humidity. Thus an outdoor environment of $35{ }^{\circ} \mathrm{C}$ poses a higher heat stress in Hong Kong than in Chongqing taking into account their different humidity levels. Workplace ventilation is more effective an intervention for the climate of Chongqing than that of Hong Kong.

\section{Markets as institutions}

The supply and demand equilibrium of labour market forms an industry level institution that to some extent determines the demography of the construction workforce, workload and organisational responses to formal safety rules. The comparative analysis revealed that while Hong Kong had a serious labour shortage and was struggling with an ageing workforce, contractors in mainland China had the advantage of selecting from a large rural labour pool, and therefore had a workforce of better 
physical health to survive heat. The market in Hong Kong was in a particular period of time that where the government had invested in a number of large infrastructure projects to boom economics, resulting in a serious shortage of skilled labour, while importing of migrant workers was restricted by legislation (e.g., South China Morning Post 27 May 2014). This was translated down to site management, resulting in the high workload over the limited number of workers. Moreover, project organisations hesitate to take any disciplinary action over unsafe behaviours that might lead to workers' dissatisfaction and turnover. For example, the workforce of residential building maintenance works was particularly characterised by a lack of discipline and low safety awareness. OHS legislation required workers to wear safety helmets all the time during work, however, workers believed "We are working at people's home - this is not a construction site." Therefore the negligence of such rules had been a norm among maintenance workers. When a non-compliant worker was caught by the regulator's inspector, his employer, the main contractor, would be prosecuted and fined for an amount of HK\$1,000 to 3,000. In such cases, the contractor chose to pay the fine instead of disciplining the worker. "If they insist to do it their way, we cannot command them to wear the helmet. There are more jobs than workers in the market at the moment. If they are unhappy and quit their job, how can you have the time to find a suitable worker? The project will be delayed." (Manager, Hong Kong site) This indicates that companies' cost equation was conditioned by the influence of the labour market, under which contractors found it a more economic option to pay for the fines caused by workers' unsafe behaviour (e.g., not wearing a helmet) than to enforce the safety rules.

\section{Financial incentive structures}

At an organisational level, the financial incentive structure built into the project human resource management system constitutes another strong influential institution to impact on working hours and workload, two major risk factors of heat stress. A clear difference in financial incentive structure in the Hong Kong sample was seen between company-based workers and project-based workers. Company-based workers were paid on a monthly basis on permanent contract with main contractors. They had longer daily working hours and lower hourly rate on a project, in exchange for a better job security and welfare of paid weekends and public holidays. In contrast, project-based workers earned a higher daily wage but were not paid for days without work due to extreme weather or public holidays, thus have less job security and relatively higher hourly workload. However, the teams have more autonomy to plan their work and normally complete their daily work with more efficiency. In the Chongqing sample, a clear difference was observed between local and migrant workers. The local workers were paid on monthly basis, having a standard daily working hours and flexible paid holidays. The migrant workers were paid a lump sum for an agreed volume of work or by daily wages, working without weekend or public holidays. Such a financial incentive mechanism drove them voluntarily working around clock. "Everybody wants to complete his work as quick as possible to get the money and move to the next project!" (W005) Therefore although the work was all self-paced, which was suggested as an effective work regimen to prevent heat stress, the financial incentive structures work as invisible rules of pacing the work. The different patterns of financial incentive structure and their associated heat related risks are summarised in Table 4. 
Table 4. Financial incentive structures and their consequential work routines

\begin{tabular}{|c|c|c|c|c|c|}
\hline & & Payment & $\begin{array}{l}\text { Weekend \& } \\
\text { public holidays }\end{array}$ & $\begin{array}{l}\text { Daily working } \\
\text { hours }\end{array}$ & Major heat related risks \\
\hline \multirow{2}{*}{$\begin{array}{l}00 \\
0 \\
0 \\
1 \\
00 \\
0 \\
0 \\
\text { 工̃ }\end{array}$} & $\begin{array}{l}\text { Company- } \\
\text { based }\end{array}$ & $\begin{array}{l}\text { Monthly } \\
\text { salary }\end{array}$ & Yes & 7 a.m. -7 p.m. & $\begin{array}{l}\text { Long working hours, } \\
\text { fatigue (sleepiness) }\end{array}$ \\
\hline & $\begin{array}{l}\text { Project- } \\
\text { based }\end{array}$ & Daily wage & Yes but no pay & 8 a.m. -6 p.m. & $\begin{array}{l}\text { Psychological stress, high workload, } \\
\text { fatigue (lack of energy) }\end{array}$ \\
\hline \multirow{2}{*}{ 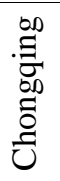 } & Local & $\begin{array}{l}\text { Monthly } \\
\text { salary }\end{array}$ & $\begin{array}{l}\text { Yes with } \\
\text { flexibility }\end{array}$ & 9 a.m. -5 p.m. & -- \\
\hline & Migrant & $\begin{array}{l}\text { Daily wage } \\
\text { or lump sum }\end{array}$ & $\begin{array}{l}\text { No, working } \\
\text { every day }\end{array}$ & Around clock & $\begin{array}{l}\text { Voluntary long continuous work, } \\
\text { compacted workload }\end{array}$ \\
\hline
\end{tabular}

\section{Institutional interventions}

Institutional interventions on heat stress were found in two ways, from top down formal guidelines and from bottom up on organisational or individual initiatives. The formal guidelines for heat stress management are summarised in Table 5. Scientific heat stress management guidelines (major documents include Doc. 1-6 in Table 5) have been developed for decades in the ergonomics field originating from experimental research in the UK (see a summary of early research in Leithead and Lind 1964). The ISO 7243 (Doc. 1, 2) specifies environmental thresholds identical to the annually updated American thresholds (Doc. 6). The ISO 7933 (Doc. 3, 4) provides rational analytical models to predict the physiological consequences of heat on the human body. A heat risk management procedure (Doc. 5) has been applied as a standard procedure among professional hygienists for heat stress control, which starts from workers' report of workplace heat, leading to empirical monitoring of the workplace. The recorded workplace heat stress is then compared against the specified thresholds. In the case where workplace heat stress exceeds the thresholds, the rational models are introduced for more specific analysis, the result of which is to trigger engineering control, complemented by administrative control. These procedures are widely adopted to evaluate and manage workplace heat stress in the 'hot work industries' such as steel mills, resulting in similar guidelines in many countries (cf. Rowlinson et al. 2014). However, the equivalent guidelines in China (Doc. 7, 8, 9) were not specified to be applicable to construction work under climatic heat stress.

Table 5. Major institutional interventions on heat stress management for document analysis

\begin{tabular}{|c|c|c|c|c|}
\hline No. & Document title & Year & Issuing body & Remarks \\
\hline 1 & Hot environments - estimation of the heat stress on working man, based on the WBGT-index (ISO 7243) & 1982 & $\begin{array}{l}\text { International Standards } \\
\text { Organization }\end{array}$ & Abolished \\
\hline 2 & Hot environments - estimation of the heat stress on working man, based on the WBGT-index (ISO 7243) & 1989 & Ibid. & \\
\hline 3 & $\begin{array}{l}\text { Hot environments - analytical determination and interpretation of heat stress using calculation of the } \\
\text { Required Sweat Rate (ISO 7933) }\end{array}$ & 1989 & Ibid. & Abolished \\
\hline 4 & $\begin{array}{l}\text { Ergonomics of the thermal environment Analytical determination and interpretation of heat stress using } \\
\text { calculation of the predicted heat strain (ISO 7933) }\end{array}$ & 2004 & Ibid. & \\
\hline 5 & Heat stress and heat strain: Threshold Limit Values physical agents 7th Edition Documentation & 2009 & $\begin{array}{l}\text { American Conference of } \\
\text { Governmental Industrial } \\
\text { Hygienists }\end{array}$ & $\begin{array}{l}\text { Annually } \\
\text { updated }\end{array}$ \\
\hline 6 & 2013 Threshold Limit Values for chemical substances and physical agents \& Biological Exposure Indices & 2013 & Ibid. & \\
\hline 7 & Hot environment - estimation of the heat stress on working man based on WBGT-index (GB/T 17244) & 1998 & China's National standard & \\
\hline 8 & Occupational exposure limits for hazardous agents in the workplace Part 2: physical agents (GBZ 2.2) & 2007 & Ibid. & \\
\hline 9 & Classification of occupational hazards at workplaces: occupational exposure to heat stress (GBZT 229.3) & 2010 & Ibid. & \\
\hline 10 & Draft guidelines for climatic heat prevention & 1960 & China's National guidelines & Abolished \\
\hline 11 & Notice for administering guidelines on climatic heat stress prevention measures & 2012 & Ibid. & \\
\hline 12 & Measures of labour protection in hot weather in Chongqing Municipality & 2007 & Chongqing Municipality & \\
\hline 13 & Guidelines on site safety measures for working in hot weather & 2008 & $\begin{array}{l}\text { Hong Kong Construction } \\
\text { Industry Council }\end{array}$ & \\
\hline 14 & Risk assessment for the prevention of heat stroke at work (3/2009-1-OHB-122) & 2009 & $\begin{array}{l}\text { Labour Department, Hong } \\
\text { Kong government }\end{array}$ & \\
\hline
\end{tabular}


The only set of national guidelines applicable to climatic heat stress was a draft document issued in 1960 (Doc. 10), consisting of empirical advice on health surveillance, medical support, drinking water provision, work rotation, etc. This set of guidelines was almost unnoticed for half century until its replacement by the 2012 updated guidelines (Doc. 11). Known as a region with extremely hot summers, Chongqing Municipality issued a set of regional guidelines in 2007 (Doc. 12). Both guidelines suggested environmental thresholds linked to administrative actions, based on daily forecasted maximum temperatures (see Table 6 for details). In spite of a lack of evidence base, a clear formal institutional intervention was in place.

Table 6. Thresholds systems in Chongqing’s 2007 regional guidelines and China’s 2012 national guidelines

\begin{tabular}{lll}
\hline $\begin{array}{l}\text { Daily maximum } \\
\text { air temperature }\end{array}$ & 2007 Chongqing regional guidelines & 2012 national guidelines \\
\hline$\geq 40^{\circ} \mathrm{C}$ & $\begin{array}{l}\text { Stop work or control workplace } \\
\text { temperature under } 37^{\circ} \mathrm{C} \text {, exceptions } \\
\text { justifiable by “production requirement” }\end{array}$ & $\begin{array}{l}\text { Stop all outdoor work except safety and security } \\
\text { work or works of public interest }\end{array}$ \\
$\geq 37^{\circ} \mathrm{C},<40^{\circ} \mathrm{C}$ & $\begin{array}{l}\text { Daily work hours } \leq 6 \text { hours; stop work } \\
\text { during } 12 \text { pm to } 4 \mathrm{pm} \text {; high temperature } \\
\text { allowance paid }\end{array}$ & $\begin{array}{l}\text { Daily outdoor work } \leq 6 \text { hours; continuous work time } \\
\text { controlled under national threshold; no outdoor work } \\
\text { during the hottest three hours }\end{array}$ \\
$\geq 35^{\circ} \mathrm{C},<37^{\circ} \mathrm{C}$ & Caution & $\begin{array}{l}\text { Control temperature under } 33^{\circ} \mathrm{C} \text { or, arrange work } \\
\text { rotation; high-temperature allowance to outdoor } \\
\text { workers; stop outdoor work for overtime, pregnant } \\
\text { or adolescent workers }\end{array}$ \\
\hline
\end{tabular}

By the time of the field study, Hong Kong had two sets of guidelines relevant to heat stress management, including a set of draft guidelines issued by Construction Industry Council (Doc. 13) and a workplace heat risk assessment checklist published by the Hong Kong government (Doc. 14). The guidelines suggested responsibilities of stakeholders of a construction project, followed by description of symptoms of heat illness and their treatment. The checklist recommended a subjective assessment method. Neither of the two guildelines adopted an enviromental threshold system.

It was found in the Chongqing field study that the specified thresholds system was not in use, and not even known by anybody. However, work regime did respond to extremely hot weather, where work time would be negotiated between gangers and managers, typically resulting in suspension of work between 11 a.m. and 4 p.m., during which workers rested in their air-conditioned on-site dormitories. However such an arrangement was not made based on concerns of human safety but an adaptation to maximise work production. The reason given by manager was "Because the steel would be too hot to be touched, and all the building materials would be unfit for work.” (M007) The site-based dormitory and the inadequacy of management infrastructure on site allowed flexibility for workers to make up the work during cooler time of the day. This was indicated by workers' responses to the question "what is the most effective measure of preventing heat stress", to which all Chongqing migrant workers nominated their dormitory on site, cross-validated by managers' interviews and researchers' observations. In contrast, their Hong Kong counterpart typically nominated "working slowly" and "shelter at workplace". 
In the Hong Kong sites, our field study found that neither of the two guidelines was in use, partly because the existing guidelines were not actionable. Most construction sites were practising a formal risk assessment procedure as part of the project safety management system, in which climatic heat stress was not listed among the risks. Interstingly, two sites were taking initiatives to implement a threshold system linked with managerial actions, one took the American Heat Index chart (c.f., www.weather.gov), another took the Canadian Humidex chart (c.f., www.ccohs.ca). Frontline staff tried to connect the environmental thresholds with an action plan. Site nurses watched over temperature and humidity reported by the Observatory, synthesised them into Humidex by looking up a chart, locating them in one of the five coloured zones. The colour will then be flagged at the entrance of the site, or any visible location of the site. Meanwhile the information was sent through SMS messages to all site supervisors' mobile phones (Figure 3). Managerial actions were taken at the 'orange zone', on which one break was given in the afternoon session, and at the 'red zone', which resulted in an additional break in the morning session.

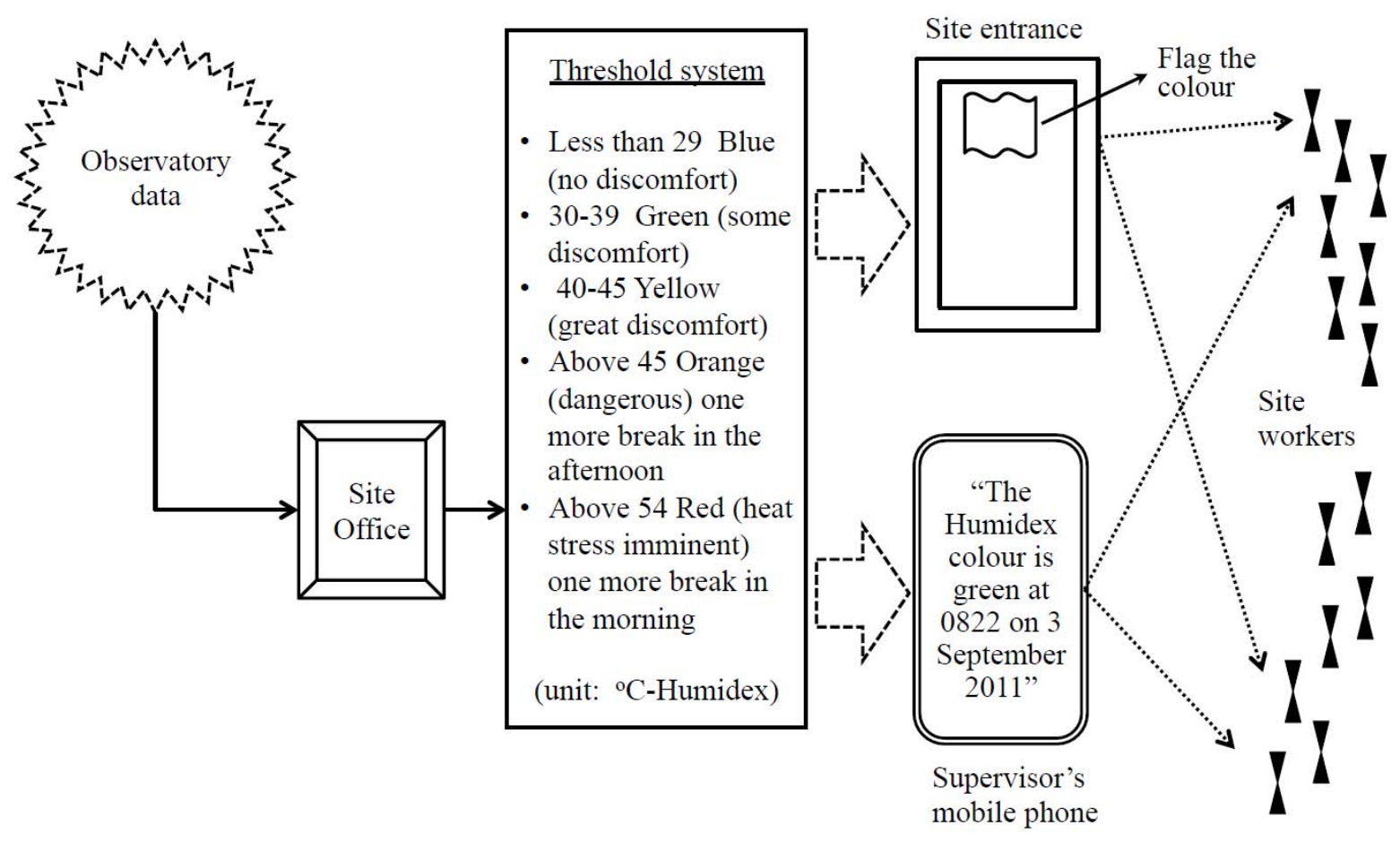

Figure 3. Hong Kong practice: materialising formal institutions

Apart from the threshold system, the other recognised effective interventions by both samples are engineering controls (shade and ventilation), providing drinking water, first aid and buddy support. The differences between the two samples are listed in Table 7. A clear pattern can be seen that the Chongqing sample relies more on informal and passive measures, while their Hong Kong counterpart identifies more with formal institutions. 
Table 7. Differences in the effective interventions identified in the two studies

\begin{tabular}{|c|c|c|c|}
\hline \multirow{3}{*}{\multicolumn{2}{|c|}{$\begin{array}{l}\text { Source of information of } \\
\text { the guidelines }\end{array}$}} & \multirow{4}{*}{$\begin{array}{l}\text { Chongqing sample } \\
\text { Public media } \\
\text { Personal networks }\end{array}$} & \multirow{4}{*}{$\begin{array}{l}\text { Hong Kong sample } \\
\text { Training } \\
\text { Informed by supervisor } \\
\text { Internet research (manager's job) }\end{array}$} \\
\hline & & & \\
\hline & & & \\
\hline & & & \\
\hline \multirow{5}{*}{ 总 } & Reactive & Ageratum Liquid (Chinese medicine) & Report to supervisor \\
\hline & Preventive & None & Mechanical aids \\
\hline & & & Prohibit alcohol \\
\hline & Administrative & Air conditioned dormitory + self-pace & Regular and compulsory breaks \\
\hline & Educative & Toolbox talk & Formal training \\
\hline \multirow{2}{*}{\multicolumn{2}{|c|}{ Threshold system }} & Specified in formal institutions & Absent in formal institutions \\
\hline & & Ignored in practice & Trying to establish in practice \\
\hline
\end{tabular}

In both contexts, the heat stress guidelines were found not working. The hazard of heat stress was however reversely coped with in the two societies, reflecting their respective institutional environments. The guidelines in Hong Kong were not in use because of its under-specification and thus space for organizational initiative, while the well-specified guidelines in Chongqing were ignored as one of the many regulations that were not necessarily materialised. The Hong Kong sites tried to solve the problem by establishing their own formal rules to complement the absence of a threshold system. The Chongqing sites were characterized by a lack of management infrastructure similar to the situation of Hong Kong in the 1990s (Lingard and Rowlinson 1998); policies and regulations existed in a more symbolic sense but were not materialised. Companies operating in such an environment tried to ignore their occupational safety and health responsibilities for profit to survive the market while the workers were making self-initiatives to keep themselves safe at work. This will be further discussed in the following sessions.

\section{Institutional logics}

The institutions identified in previous sessions are diverse and in effect driving behaviours to contradictive directions. However, actors do have consistency in their decisions of selective conformity to certain institutions at certain contingencies. The concept of institutional logic explains this internal consistency. In the following sections we present two levels of institutional logics generated from the grounded theory, at society level are two pairs of logics from comparison of the two contexts: a religion logic (Confucianism vs. pragmatism) and a market logics at society level (rational market vs. individualism); at project organisational level are two different logics of processing safety in production (protection logic vs. production logic).

Historically, Hong Kong was a British colony from 1842 until 1997 when it was handed back to China. The working population is predominantly Chinese. Chongqing is a municipality in mainland China. Parallel to Hong Kong' colonial period, mainland China has gone through a radical modernization journey, undergoing revolutions and wars, followed by a changing sociopolitical system from a Chinese version of communism to a Chinese version of capitalism (or socialism). A structural change in mainland China's economic system occurred at the end of 1970s when a top decision was made to move from a state-commanded economy to a market economy. From then on China has undergone a privitisation process and become increasingly a major player in the globalising market. 


\section{Religion logics: Confucianism vs. pragmatism}

The logic of religion underpins what people believe is the truth and how people of a specific society construct reality, thus meaning from symbols. In the two populations of our study, the dominant logics of religion can be summarised as Confucianism in the Chongqing context and pragmatism in the Hong Kong context. Liu et al (2010) explain that traditional Chinese society was composed of a high culture of Confucianism and a low culture of pragmatism. Central to the culture of Confucianism is the value of benevolence (Ren), expressed as "do not do to others what you would not have them do to you" (Analects of Confucius) - a similar expression of Matthew 7:12 in the Christian Bible. Over the history, the pragmatism culture was developed when the benevolence values were translated into desired behaviours and legalised to form the Confucianism social order. The undereducated majority, who could not be bothered to make sense of the Confucian values, pragmatically did the minimum to clear the trouble of offending the law in order to get on with their day-to-day business. Pragmatism can thus be defined as the situational ethics that embraces "the end justifies the means" (Miesing and Preble 1985) and an inclination to achieve the material goals by the most convenient means.

The Confucianism logic in the Chongqing sample was expressed in a manager's statement on the reciprocity of safety and production: "According to the Three Cardinal Guides, a king should be a role model to his subjects. Apply to our time, it means a manager should be a role model to his workers; a boss should be a role model to his employees. Managers should show their benevolence and take care of workers' welfare; workers will then follow their example to work hard to help managers to achieve their production goals."(M006, Chongqing site) Here the legitimacy of safety is the employer's benevolence to workers. The pragmatism logic in the Hong Kong sample was manifested in a worker's complaint about the project organisation, "The project is already behind schedule! We have to work overtime; (because) everybody is exhausted by safety!" (STFP08, Hong Kong site) Here safety is an obligation to be dealt with in order to get on with the production tasks.

\section{Market logics: rational market vs. individualism}

Market logic is the commodification of human activities (Friedland and Alford 1991), bringing in values of individualism, willingness to work for gain, trading leisure for income at the margin, and victim-blaming (DiMaggio 1994). The two samples reflected two different historical stages of a capitalist market. The Chongqing sample subscribed to a rational market logic which legitimises the 'economic man' who makes rational choices to maximise utility (Simon 1957), while firms are destined to maximise profit, as assumed by the neoclassical economists (Weintraub 2002). Meanwhile the Hong Kong sample reflected a more mature individualism in an affluent society where individuals expect more rights and autonomy (Turner et al. 1986) while firms are taking up more social responsibilities (Loosemore and Phua 2010). In the following section, the manifestation of market logic is illustrated with the workers' attitudes toward the practice of acclimatisation protocol.

The acclimatisation protocol

Acclimatisation is a physiological status that the human body adapts to environmental heat with more efficient sweating while preserving salt. A person not used to heat needs at least three days to get 
acclimatised before taking up a full workload. This literally means the practice of acclimatisation protocol indicates a discernible productivity loss to the team and the project. When asked whether newcomers should be given time to work slowly to adapt to heat, a worker in the Chongqing site believed it totally unnecessary, giving the reason as, "It is one's own responsibility to make sure he has enough capacity to do the work he chooses to do. If he wants to earn the high wage, he has to work fast. If he cannot keep up, then he has to leave.” This clearly demonstrates a victim-blaming value and a rational assumption of the individual. By the same logic, employers were assumed to focus on activities of minimising cost and maximising profit. When asked why companies did not inform them about the new guidelines, another worker said, "How can they tell us? They'd rather keep us ignorant so that they don't have to pay the allowance! They are thinking how to put money into their pocket!” In contrast, in the Hong Kong study both workers and managers recognised that the acclimatisation protocol was necessary for working in heat, although they acknowledged it was not fully practised, indicating a better acceptance of individual rights and wellbeing. The influence of the society level logics is to be further discussed in the following sections.

\section{The organisational level logics of processing safety in production}

Situating safety in its organizational context, and organisation in its societal context, two different logics of processing safety in production emerged: a protection logic in the Chongqing sites and a production logic in the Hong Kong sites. They are elaborated as follows.

The protection logic

Explicated in the Chongqing study, the protection logic assumes construction work is inherently dangerous while safety cannot coexist with work. Safety is in the workers' personal interest while profit is in the employer's interest; both protect their own interest by nature, and on top of which going an extra mile to take care of the interest of their counterparts. As illustrated in previous sections, the Confucius logic legitimises safety as reciprocity of benevolence between the workers and the employers, where employers are expected to be a benevolent leader to take care of their employees' wellbeing, in return for the individuals' loyalty to the organisation expressed by diligent production. The rational market logic renders a self-survival individual identity and a profit-seeking organisational identity. Thus workers intrinsically protect their personal interest by staying safe as much as they can. If employers can demonstrate their effort in safety, workers will read it as a sign of benevolence and be motivated to be more efficient in production work in reciprocity, and vice versa. A manager gave an example to elaborate his logic: "I once saw a supervisor command a poor old worker to climb up a dangerous place, 'You! Go and get that board for me!' If a supervisor is so careless about workers' safety and dignity, how can he expect workers to work for him sincerely?” The underlining protection logic explains workers' self-discipline for a safer work regime in the absence of a safety management infrastructure.

The production logic

Influenced by the society level market logics, the production logic explicated in the Hong Kong study turns safety into an extra task, an institutional obligation, in addition to the production work. In an established, highly formalised systemic context, the rules play the role of interpreting and 
materialising safety, while both managers and workers are accountable to the rules, instead of safety itself. Therefore workers have extra "safety" work to do, e.g, housekeeping, just before the arrival of every important visitor to the site. While programmes such as Safety Awards are not necessarily awarded to the safest worker. When asked if the management team were initiating the safety programmes for workers' wellbeing, a worker said, "Not at all! They are doing it for their own rice bowl!” (STFP08) The worker was cynical for being overloaded by the extra tasks generated by the safety programmes that did not actually make them safer. After all, they were paid for completing the production work, not for entertaining the safety programmes which meant nothing but the managers' performance indicator! Decoupled from its meaning, safety becomes a source of workers' cynicism. The two logics are summarised in Table 8.

Table 8. Institutional logics of processing safety in production

\begin{tabular}{|c|c|c|}
\hline & Protection logic (Chongqing sites) & Production logic (Hong Kong sites) \\
\hline Religion logic & Confucianism & Pragmatism \\
\hline Market logic & Rational market logic & Individualism \\
\hline Legitimacy of safety & Reciprocity of benevolence & Compliance to formal rules \\
\hline What is safety & Free from work & Another production task \\
\hline What is production & In spite of safety risks & Core business of every party \\
\hline $\begin{array}{l}\text { Incentive structure for } \\
\text { safety }\end{array}$ & $\begin{array}{l}\text { Individual-initiatives informed by } \\
\text { public media }\end{array}$ & $\begin{array}{l}\text { Organisational initiatives required by } \\
\text { external institutions }\end{array}$ \\
\hline Enablers of safety & $\begin{array}{l}\text { Onsite accommodation; flexible } \\
\text { working time }\end{array}$ & $\begin{array}{l}\text { Formal rules; management } \\
\text { infrastructure }\end{array}$ \\
\hline Who owns safety & Worker & Regulator, then employer \\
\hline $\begin{array}{l}\text { Interest of the } \\
\text { counterparty }\end{array}$ & Profit & Individual freedom \\
\hline Accountable to & Personal wellbeing & External institutions \\
\hline Employee's core question & To work, or to stay safe? & Which task to prioritize? \\
\hline Employer's core question & Safety, or run the business? & $\begin{array}{l}\text { What's the minimum cost to get away } \\
\text { with safety for production? }\end{array}$ \\
\hline $\begin{array}{l}\text { Employer's strategy to } \\
\text { survive the market }\end{array}$ & $\begin{array}{l}\text { Forgetting about safety is more } \\
\text { profitable than acknowledging it. }\end{array}$ & $\begin{array}{l}\text { Keeping non-compliance workers } \\
\text { happy to get the project delivered is } \\
\text { more important than the safety } \\
\text { performance of the project. }\end{array}$ \\
\hline Core issue & Contradict safety and production & Decouple safety from its meaning \\
\hline What works & Benevolent leadership & Authentic leadership \\
\hline
\end{tabular}

\section{Institutions and institutional logics as premises of actors' decisions}

Having explained the two core concepts, in the following section we present more detail on how institutional environments and institutional logics interact to influence individual decisions on their behaviours in the two contexts on the patterns of fatigue and alcohol drinking behaviour. 


\section{Case 1: Fatigue}

Two major dimensions of fatigue, sleepiness and lack of energy, were found prominent in the Hong Kong study, but not in the Chongqing study. Lack of energy refers to the depletion of physical strength after long continuous work, or situations of working with an empty stomach or immediately after lunch. Sleepiness is determined by the quantity and quality of sleep; the former influenced by daily working hours, travelling time and time for off-work recreation, the latter by workers' personal health and work-life balance.

In Hong Kong, unless being given a special permission, the legal daily working time for construction work was constrained to between 7 a.m. and 7 p.m. by the Noise Control Ordinance. This constraint, combined with a tight project schedule, resulted in compacted workload and a short lunch break. The long continuous work during the day was further aggravated by workers' voluntary cancellation of breaks from time to time. For example, a team of rebar workers decided to cancel their afternoon tea break every Wednesday in order for an early off for the weekly horseracing night. Such collective decisions are driven by the market logic of individualism, driven by the market logic, of which recreation activity is of utmost importance as a materialisation of individual freedom. Consistent with the logic, when an experienced worker was asked to suggest effective intervention for heat stress management, he suggested a "compulsory break in the morning session". "Compulsory", he emphasised, "Everybody, the whole site, stop work during 10 to 10.30 a.m. without exemption.” He said this because under the production pressure and a norm of rushing the work, breaks could not happen unless they were formalised to the extent of a law. In this case, the worker drew on formal rules to justify his safety concern and to counter the peer pressure of conforming to the norm. Out of the same logic, off-work abuse of alcohol or drug, which impacts on both quality and quantity of sleep, was common in the Hong Kong workforce as a relief from the highly controlled workplace. Such decisions at individual or team levels are legitimised by the society level logic that individuals work to make money for more freedom.

In Chongqing, the time range for construction work was more flexible in the absence of noise-control legislation, and therefore the migrant workers often worked incredibly long working hours, yet in a much lower intensity compared to their Hong Kong counterpart. The work was largely self-managed, and proportionally mixed with idling due to the lack of an efficient formal coordination system. Researchers observed that the concereters' team spent a whole morning idling, due to miscoordination of the concrete pump truck (which, in the case of heat stress, did not make their life easier as they had to stand around on a rooftop of $14^{\text {th }}$ floor under strong sunlight). In an extreme case, the concreters mentioned that they once worked continuously for 48 hours without sleep. "But what can you do about it? The concrete and the pump can't wait. Once started, we must complete it.” (W005) Such a situation could have certainly been made safer by work rotation arrangements. As claimed by the managers, additional labourers could be easily recruited when the project was behind schedule. However an option of job rotation for concreters was never considered, nor perceived as an option at all, neither by the manager nor by the workers. Here the hiring of additional labour is legitimated as a necessary investment on successful delivery of the project for immediate or future 
opportunities of profit, while its use for sharing workloads for safety is an unnecessary extra cost and therefore excluded from management attention and left in workers' ignorance. The rational market logic shaped a collective blindness to such a possible institutional solution (a possibly established practice).

But having said that, the religion logic and the organisational level logic of processing safety in production created another pathway for the Chongqing sites to minimise the risk of fatigue in spite of the long working hours. The migrant workers were accommodated in the air-conditioned on-site dormitories, which, compared to their Hong Kong counterpart who normally spent three hours daily in travelling between home and site, enabled much flexibility for self-paced work. The self-managed work regime has also enabled the work to be conducted at cooler times of the day during hot weather. Meanwhile workers at individual level made decisions for their actions to prioritise their physical safety and health over other formal and informal institutions. Such a decision-making preference is underpinned by the institutional logics that safety is in the workers' self-interest and production is a reciprocity to the employer's benevolence, as illustrated by the following example. It was also underpinned by the rational market logic that the migrant workers accepted a lifestyle of living away from their families and were willing to trade leisure for income.

During lunchtime, researchers were surprised to find that a well-equipped site canteen was left empty, while workers rushed to a street food market with very poor hygiene conditions right outside the site. When workers were asked whether their choices were based on price difference between the canteen and street food, the answer was 'No'. Instead, the key factor that led to such decision was "time for a nap”. To buy a set lunch in the official canteen, workers needed to go through a rather formal and time-consuming procedure. In contrast, the private street food market was operated in a casual way, building on a sense of in-group trust, where workers simply threw their money into a bucket and took a plate to select their own favoured food, thus they could finish lunch quickly to rush back to the dormitory for a nap before the afternoon work. The different paths leading to fatigue are illustrated in Figure 4.
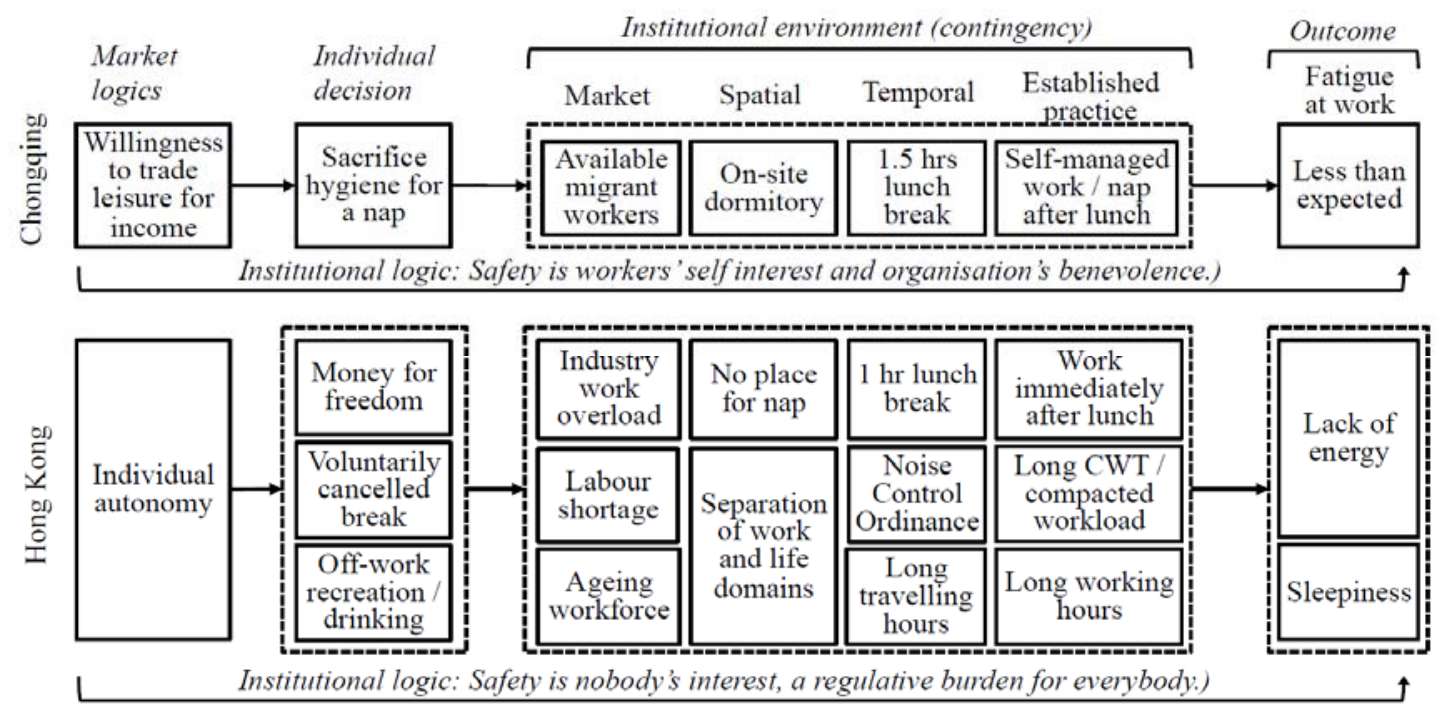

Figure 4. Institutional logics and institutional environments that shape fatigue patterns 


\section{Case 2: Alcohol drinking behaviour}

In relation to heat stress, alcohol drinking is a risk that dehydrates the body therefore increases one's vulnerability to heat illness. There were formal rules of prohibiting alcohol in both Hong Kong and mainland China for general safety reasons. Our site study found such a formal institution was not seriously practiced in either context. Instead, a norm of alcohol drinking prevailed. However, the two samples arrived at their decisions from their respective logics. The Chongqing workers argued that they drank alcohol for preserving their personal health. A worker in the Chongqing site described that he drank a bottle of beer during lunch in summer for "cooling down the body" and some rice wine over dinner "for health". It was observed that beer was an indispensible drink during lunch among the workers. While it is a common sense of the traditional Chinese society that regular drinking of small amount of rice wine helps with personal health by keeping the body's circulatory system active. In contrast, their Hong Kong counterpart drank alcohol as stimulator. A female worker in the Hong Kong site mentioned that she needed to drink some rice wine during work "to give me strength to sustain this heavy work" in spite of her awareness that she would be dehydrated. Similar justification was given by a group of rebar workers for drinking beer when working in hot weather: "we need energy to survive the heavy work in hot weather”. The long continuous work time and compacted workload in Hong Kong sites pressured a need for aggressively booming physical strength and suppressing fatigue. The need for stimulators at work reflected declined physical fitness among the ageing workforce in Hong Kong. Observations and personal health records showed that the Chongqing workers were in excellent fitness while their Hong Kong counterparts were overweight with poor physical fitness.

Among the frontline managers, workers' alcohol drinking habit was well accepted through their respective institutional logics. A manager in the Chongqing site rejected the idea of enforcing the rule of alcohol prohibition, because, “People like it. You can’t (and shouldn't) prohibit people's hobby.” Such a reasoning logic identifies with the image of a benevolent manager who lends empathy to their workers. In the Hong Kong site, a manager described the reality on site as, "The rebar trade has a norm of drinking alcohol. We can't stop them from doing so, because it is their habit." Such a reasoning logic is consistent with the finding reported earlier in the Markets as Institutions section, that the primary organisational goal in Hong Kong is to keep workers happy for efficient production. Thus in the case of institutional intervention the project organisation took initiative to set up formal regime to manage heat stress for a perceivable better working condition, while in this case managers chose not to offend the norm of unsafe bahaviour in order to maintain the team morale.

Furthermore, the norm in some cases 'caused' workers' alcohol-drinking behaviour as extension of the two logics. For example, in the Hong Kong site a plasterer working for a subcontractor stated that he drank alcohol over lunch, because, "I have to drink with my boss, or he wouldn't hire me for the next job!" While in the rebar team, a worker that did not drink was quickly alienated by the team and had to quit his job for another project. In such cases, the norm was internalised as a social obligation and non-conformer risk losing his in-group identity or future job opportunities. Conversely, a plasterer in the Chongqing site stated that he believed the rule of alcohol prohibition should be enforced 
because, "Drinking is good for me but not good for the whole." He further elaborated that alcohol would stimulate fighting among the team members and therefore damaging team harmony, resulting in lower productivity. Here the worker was willing to lend his benevolence to his organisation by sacrificing his 'personal health' to productivity - the perceived interest of the organisation. In the Hong Kong case, both the workers and the managers made pragmatic adaptations to the institutions that embody unsafe behaviour for a general goal of getting the job and getting it done. While in the Chongqing case there is a clear division of interests between the employer and the workers' safety and production goals are achieved through exchange of benevolence between the two interest groups. The contrasts between the two samples are summarised Table 9 .

Table 9. Comparison of alcohol drinking related decisions

\begin{tabular}{|c|c|c|}
\hline & Chongqing sample & Hong Kong sample \\
\hline $\begin{array}{l}\text { Worker's personal motive } \\
\text { (market logic) }\end{array}$ & Drink for health & $\begin{array}{l}\text { Drink for stimulation (get the job } \\
\text { done to earn money and freedom) }\end{array}$ \\
\hline $\begin{array}{l}\text { Manager's attitude (market } \\
\text { and religion logic) }\end{array}$ & $\begin{array}{l}\text { Approve and support (sympathetic to } \\
\text { workers' 'hobby') }\end{array}$ & $\begin{array}{l}\text { Beyond control, let go (keep } \\
\text { workers happy for production) }\end{array}$ \\
\hline $\begin{array}{l}\text { Worker's socialized decision } \\
\text { (religion logic) }\end{array}$ & $\begin{array}{l}\text { Comply to formal rule to give up } \\
\text { drinking for the benefit of 'the whole' }\end{array}$ & $\begin{array}{l}\text { Conform to social norm to drink } \\
\text { with their boss (for future job } \\
\text { opportunity) }\end{array}$ \\
\hline
\end{tabular}

\section{DISCUSSION}

\section{Connecting with existing institutional theories}

The concept of institution emerges in our study generally shares the meaning with that defined by the new institutionalism school (Powell and DiMaggio 1991). North (1990) defines institutions as 'rules of the games', i.e., external constraints on behaviours, among which informal institutions are devised as means of reducing transaction costs caused by the formal institutional systems. An alternative perspective sees institutions as self-enforcing expectations manifested in regularity of behaviours (Brousseau et al. 2011), thus the concept can be extended to include established practice and values. More broadly, Elinor Ostrom (1990) defines institution as "regularity of human activity”. On effective institutional interventions, Ostrom (1990) suggests a mix approach of centralisation and selforganisation through continuous trial-and-error at local level. A justification for our inclusion of local climate in the pool of institutions can be found in Ostrom's (Ostrom et al. 1994, Ostrom 2005) framework for institutional analysis that jeopardizes 'biophysical and material conditions' with 'attributes of community' as alternative categories of rules.

The concept of institutional logic was first initiated within the new institutionalism literature as a critique of its failing to address the influence of the wider society context on the institutions (Friedland and Alford 1991). Friedland and Alford suggest five central logics of a modern Western society that shape interpretation of meaning and legitimacy: the logic of capitalist market, which is commodification of human activities; the logic of state, which is rationalisation and regulation of human activity through bureaucracy and hierarchy; the logic of democracy, which is participation and institutional control over government (see also Pettit 2008); the logic of family, which is motivation of human activity by unconditional loyalty to an in-group; and the logic of religion (or science), which 
is people's essential belief of what is truth and reality. Thornton and Ocasio (1999) picked it up and further developed the institutional logics perspective. The empirically studies by Thornton (2001, 2004) bring to light the change of logics in the publishing industry over five decades where a personal or professional logic was gradually overwhelmed by a market logic. Only recently, the institutional logics perspective is considered as a mature theoretical framework to replace the new institutionalism lens (Thornton et al. 2013).

We find it necessary to keep both concepts that function at different levels of decision-making premises. In short, the definitions of institutional logics in the business literature can be summarised as 'logics as institutions', while the definition defined by our data can be summarised as 'logics of institutions'. Whilst institutions constitute the current normative and rational environment of individual and organisational actions and form a repertoire for the actors to draw on, institutional logics are the central values that determine actors' intended and bounded rationality through shaping attention, legitimacy and meaning and selective conformity. Institutional logics provide the internal connection between individual decisions with the higher-level systemic contexts. It is not 'another institution' but the logic underpinning the activated institutions as a whole. The interrelationships between the two concepts and actor's decisions and actions are illustrated in Figure 5.

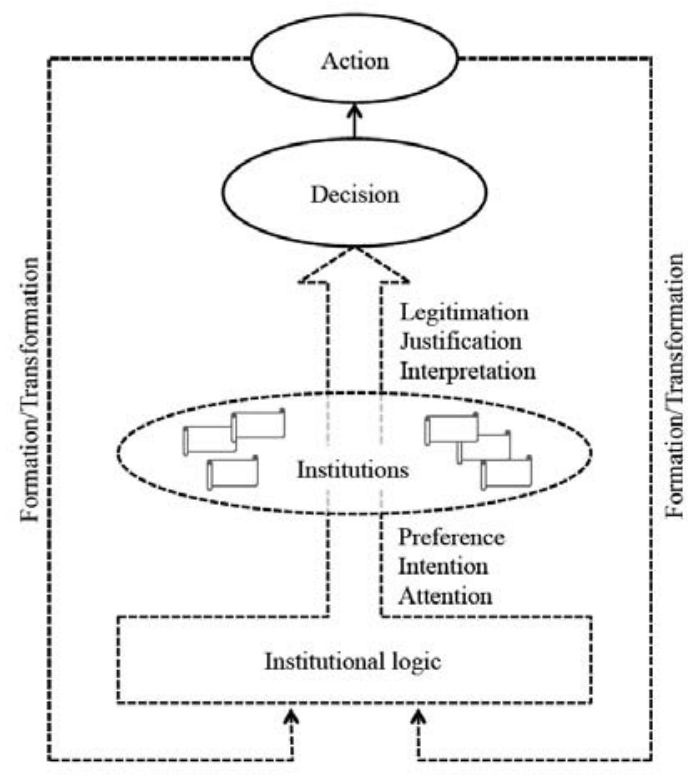

Figure 5. Interrelationships among the concepts

The term market is used at two levels in this paper: one under the 'Markets as Institutions' section, referring to the market 'out there' which works as an institution to shape organisational and individual behaviours such as hiring, turnover, or safety initiatives; another use of the term is under the 'Market Logics' section, referring to the rationale of capitalisation of human activities or goods. The possibility of hiring additional labour is a condition of supply-demand equilibrium of the market (as an institution. Our findings show that organisation appeals to this institution when there is a need of profit making, and is blinded to this option when it is a problem of health and safety. The market logic is a lens of making sense of how the society works. Whilst existing institutional theories generally 
recognise one market logic (Thornton 2004), our data suggest it can be further defined in distinctive characteristics, in this case, a rational market logic (assuming 'economic man' of individuals and efficiency as the default organisational goal), or individualism (assuming individual rights and freedom in contrast to a collective identity).

On explaining the effectiveness of institutional interventions, Roland (2004) classified institutions by their speed of change into a spectrum of fast-moving and slow-moving institutions with political institutions at the fast end and social norms at the slow end. The success of institutional change is seen as a result of fit or competition between the fast- and slow- moving institutions, in that the former can be changed top-down overnight while the status of the latter that can enable or paralyze such a change. We are of the view that society changes through the interaction between institutions and institutional logics of the society or sector, through a collective shift in attention, meaning construction and legitimacy and therefore the activation of certain institutions and their behavioural interpretations. The change of logics takes a historical scale of time to realise and is associated with the changes in authority structure, focus of management attention, organisational strategy and resource allocation, and consequentially legitimacy and meaning of existing institutions.

Existing business literature explored areas of institutional logics as strategic resources (Durand et al. 2013); changing, blending or creating new logics (Thornton et al. 2005); logics contradiction, competition and multiplicity in organisations (Greenwood et al. 2010, Besharov and Smith 2014), etc. These are promising areas for future research in the construction field; while our differentiation between the concepts provides a new frame for structuring institutional logics analysis, e.g., some institutional logics defined in the business literature in the frame of our theory might drop into our category of institutions, and the focus of analysis might shift to the multitude of institutions and how actors attend and appeal to some but not others driven by their central logic.

\section{Implications for safety management practice}

The practical question that drives our study is why safety rules cannot control behaviours to achieve safety. To answer the question we need to redefine 'what is the problem'; the grounded theory generates a lens for frame the problem through the two core concepts, institutions and institutional logics. The concept of institution provides a lens to examine the regulating power of implicit rules in parallel with the formal rules. Specific to safety management research, the concept brings to sight of the regulating power of non-safety rules over safety behaviours, thus enables us to see how these seemingly incompatible domains are working together in shaping behaviors. The concept of institutional logic explains why some rules are having the driving power and others are ignored or avoided. Whilst safety rules are the focus of safety management, in reality there are many other active institutions outside of the safety domain controlling individual behaviour such as the financial incentive structure of the production system. The same rationale applies to explain organizational behaviour in response to safety regulations and shed light on why some regulations are ignored while others picked up and implemented (Ju and Rowlinson 2014). 
The concept of institutional logics sheds light on the internal consistency of the seemingly discrete accident causal factors scattered in multiple levels of system contexts. It explains why certain institutional interventions generate safe behaviours in one context but not another, or during certain period of time but not forever. Lundberg et al (2009) argued that causes of an incident found during an investigation reflect the assumptions of the incident model. They coined the acronym "WYLFIWYF", meaning What You Look For is What You Find also, What You Find is What You Fix, "WYFIWYF" (Hollnagel 2008). Our results suggest that the actual safety outcome is a natural outcome of the institutional logics embodied in regulations and regulatory actions, organizational production system and actions, and individual beliefs and actions. Effective intervention is not possible by transplant of institutions but through transformation of the logic which changes actors' attention, intention, and preferences of choices. The historical dimension of institutional logic suggests a realistic expectation of the time span to achieve the expected improvement and a good way to make it is to identify roadmap for organisational actions that address progressive change of institutional logics at all levels.

The interactions between institutions and institutional logics work out through the role of individuals and organisations as agents of society level institutional logics (in contrast to the passive roles of executor or offender of the rules as assumed by the new institutionalism literature). Workers draw from available institutions to decide their behaviors to achieve their own legitimate goals. For example, the Hong Kong workers chose to conform to norms of alcohol drinking for job opportunities; or to comply with formal rules of compulsory breaks to survive heat stress. Therefore although the occurrence of fatigue were normally recognised as a consequence of long working hours (Chan 2011), our results show that they are also outcomes of individual prioritisation driven by a consistent underlined logic.

The logics of processing safety in production suggest a holistic view of safety in its systemic contexts. The Hong Kong situation is not too different to that of the UK, Australia or USA (Behm et al. 2014), where under-reporting of injury rates becomes a common organisational strategy to cope with the safety-related regulations. To tackle such a problem, an institutional solution was suggested to shift the measurement of safety performance from lagging indicators (after occurrence of incidents, e.g., injury rate) to leading indicators (prior to occurrence of harm, e.g. percent of safety compliance) (Hale 2009, Hinze et al. 2013). However, our finding on Hong Kong workers' cynicism to organisational safety programmes suggests that, in an institutional environment where safety is processed in a production logic, even leading indicators can generate pragmatic coping by the organisations, with a consequence of taking safety ownership away from the workers. In cases where safety rules and procedures were found to be impractical to the specific work situation, ironically, operational staff had to skip the inflexible safety rules to achieve personal safety (see a recent European study by Blazsin and Guldenmund 2015). In such cases, safety ownership is removed from the workers, from the companies, and eventually remained with the regulators only. It is thus noteworthy that in our Chongqing study, in an environment that formal management system was underdeveloped, safety ownership was still with the workers. While in the Hong Kong study, organisational initiatives of setting up actionable environmental thresholds were fertilised by the underspecified industry level 
guidelines, motivated by organisations' need of surviving the market through retention of labourers and maintaining productivity. Therefore for the developing countries, a question merits further study would be how to develop their safety management systems without losing workers' safety ownership. While for developed societies, the role of the market on retaining safety ownership with the organisations and individuals merits further study.

In the UK, Sherratt et al (2013) examined two major discourses on safety management in construction project organisations: safety as enforcement and safety as engagement. Their analysis revealed that whilst the engagement discourse advocated a non-blame culture, the organizational accountability system however was set for enforcement through punishment of errors, which faked the engagement discourse into a means of persuasion. Consequentially, pragmatism coping was observed in both organizational and individual behaviours: company "sets rules, practices and processes at the very minimum to meet the legislative requirement", while on site "violation of safety rules was found to be inherent and accepted aspect of construction site realities”(Sherratt et al. 2013: 631). This is consistent with the production logic identified in our Hong Kong study. If the organisational safety discourses can be seen as the espoused theory of the organisation, the institutional logic of processing safety in production is the theory-in-use (Argyris and Schön 1974). The inconsistency between these two can be a source of workers' cynicism and distrust to management, as reported in our findings. As such, trust can be seen as an attribute of the organisational institutional environment (Thornton and Ocasio 2008) that indicates workers' perceived consistency between the discursive philosophy and the concrete action of the organisation.

The finding that contractors were reluctant to discipline workers' unsafe behaviours in order to keep workers happy reveals a potential inconsistency between safety and job satisfaction. The level of job satisfaction reflects workers' needs to subscribe to many different institutions that are not directly related to their personal safety and health, or are even against it. For example, the Hong Kong workers drink alcohol for "strength", for emotional relief from the highly controlled workplace (a sense of individual freedom), for being an in-group of the team, or out of a rational decision of sacrificing immediate safety for socialisation for future job opportunities. If the ultimate goal of safety management is workers' wellbeing, will it be achieved by making workers behaviourally safe but leaving them to many other social stresses? Or, will it be achieved by keeping the site a safe place but pushing the problems into workers' personal lives? These lead to another issue of interest for future research: who are the workers? Recently, we have seen a growing volume of literature of ethnographic research portraying a realistic picture of workers as authentic persons of rationality, autonomy, emotion and history of experiences in complex cultural and systemic contexts (e.g., Chan 2013, Moore 2013, Tutt et al. 2013b, Shipton et al. 2014). While we need more of such ethnographies for enriched understanding of the complexities involved, there is potential to draw insights from the existing ethnographies with appropriate institutional analysis. Meanwhile, interventions that tackle the right problem can be developed locally with the understanding of workers in mind. For example, in the case of alcohol drinking, under the protection logic in the Chongqing context where workers took initiative to preserve their personal health and safety, such an unsafe behaviour can be changed by simply providing the right knowledge and information to the workers. While in the Hong Kong 
context, the workers' problem was with the individual's intentions and priorities. The issue can be solved at different levels. At industry level, the overall workload of the industry needed to be coordinated to match the capacity of the available labour pool of the society. At project level, the problem of compacted workload can be eased by redesign of breaks and provision of on-site resting spaces. At individual level, consciously maintenance of a healthy lifestyle and physical fitness will work for coping with such a physically stressful environment.

\section{Scope of the grounded theory}

The two core concepts emerged from this specific set of data, institution and institutional logic, provide a new lens to understand the situation of site safety management and the behavioural outcomes. The Findings section focuses on explaining the two concepts by spotting out where the institutions are in the living context and how they are appealed to in response to different contingencies driven and justified by the underpinned institutional logics at society and project organisation level. Institutions including regional climate, weather, market, heat stress, spatial and temporal constraints, guidelines, established practices, social norm, team culture, management infrastructure, etc. are narrated in the Findings to illustrate how they exist and operate in the site management context and how the institutional lens could be used to formulate research problems to address the situation of safety research. The research is however not intended to provide a detailed, structured theoretical framework for empirical test, although future research is invited to do so by structuring the institutional factors based on Table 2. The two pairs of society level institutional logics and the logics of processing safety in production are generated as sub-concepts of institutional logic. They can be used as a broad theoretical framework or as standalone frames for future empirical study, though some modifications or adaptations might be needed when applied to different societal contexts. In a more general sense, the methodology introduced in this paper can be replicated for explicating institutional logics in other societal or occupational contexts. In dialogue with the research tradition of construction management field, our research works at the problem-framing stage and stops at the discovery of a set of concepts as lenses for formulation of new research problems. Further study can build on these perspectives to formulate more detailed theoretical frameworks to guide application research in the safety management field.

\section{Limitations}

Although the research commences with no presumed theoretical framework, our exploration in the field does have a central interest in explaining safety related issues. This central interest to some extent shapes the nature of our data from which the theory is generated. Noting this boundary of our data, the findings of this research do not mean to be a sociological description of the two societies. In reporting the Confucianism logic in our Chongqing sample and pragmatism logic in our Hong Kong sample, we are conscious that the Confucianism logic may well exists as a central logic in certain domains in the Hong Kong society (e.g. Liu and Fellows 2001), and vice versa the pragmatism logic in mainland China. Finally, as any grounded theory would acknowledge, it is open for densification and modification when new data is joined in future research. 


\section{CONCLUSION}

The aim of this research was to explore alternative perspectives on why safety rules couldn't control behaviours to achieve compliance. Through a grounded theory ethnographic study of heat stress management on construction sites in Hong Kong and Chongqing, two core concepts, institution and institutional logic, emerged from our analysis to offer a new lens to reframe the problem that behavioural safety has been trying to solve. The two concepts are defined by and grounded in the specific set of data. In comparison with existing institutional theories in the business literature, we define institutional logic as 'logic of institutions' in contrast to 'logic as institutions' defined by existing institutional theories. The theoretical contribution of this paper is to make a distinction between the concepts of institution and institutional logic and define them at different levels of decision-making premises. Institutions are defined as the externally imposed or self-enforcing rational or nominal premises of decisions; institutional logic is defined as the as the central values constituting the actor's core identity, the central logic of the actor's theory-in-use in attending and conforming to the available institutions. The findings section explains these two concepts in various contexts to illustrate how individual and organisational behaviours are driven or constrained by multiple institutions that are not visible in the safety domain but in effect compete with or overwhelm the safety rules. The internal consistency of individual choices and organisational decisions is explained by the concept of institutional logic, which shapes actors' attention, intention and preferences in activation of certain institutions, and their justification and legitimation of decisions based on their construction of the meaning of the activated institutions. Furthermore, two levels of institutional logics are explicated as sub-concepts. At society level, we explicated two pairs of market logics (rational market vs. individualism) and 'religion' logic (Confucianism vs. pragmatism) on individual decisions. At project organisational level, two contrasting logics of processing safety in production are explicated, i.e. a protection logic in Chongqing and a production logic in Hong Kong.

The institutional perspective provides new insights into construction safety research by giving compatibility to the behavioural effect of rational and normative constraints within and outside of the safety domain, thus to open up new trajectories for future research to examine their interactions and change. The institutional logic perspective provides a lens to examine the joint influence of multiple levels of systemic contexts over safety performance and points to ways of developing effective intervention from local context and a realistic expectation of a progressive change. The results suggest safety intervention needs to redirect its focus from promoting safety alone to addressing the institutional logics and institutional environment of the entire organisation and its societal context. Methodologically, safety research needs to redirect its focus from analysis of discourses, interviews and surveys to more authentic case-based analysis, verified through ethnographic study and triangulation of multiple sources of data. The Glaserian grounded theory approach systematically introduced and applied in this research may claim a methodological contribution to the construction management research field. In dialogue with the existing paradigm of construction management research field, this research demonstrates that the formulation of research problem can be done empirically through researcher's direct engagement with the field situation, and problem-framing is worth to be recognised as a substantial part of a formal research investigation. Seeing the unique context of construction management practice as a breeding ground of new management theories, we 
suggest theory generation research be legitimated as a viable type of research in the construction management field.

\section{REFERENCES}

Argyris, C (1952) Diagnosing defenses against the outsider. Journal of Social Issues, 8(3), 24-34.

Argyris, C and Schön, D A (1974) Theory in Practice: Increasing Professional Effectiveness. 1st ed. San Francisco: JosseyBass Publishers.

Behm, M and Schneller, A (2013) Application of the Loughborough Construction Accident Causation model: a framework for

organizational learning. Construction Management and Economics, 31(6), 580-95.

Behm, M, Lingard, H and Bruening, J (2014) Validity and reliability of dependent variables: considerations for construction safety researchers. In: Aulin, R and Ek, A S (Eds.), Proc. CIB W099 Conference: Achieving Sustainable Construction Health and Safety, pp. 609-17. Lund, Sweden, 2-3 June 2014: Lund University.

Berger, P L and Luckmann, T (1966) The Social Construction of Reality: A Treatise its the Sociology of Knowledge. New York: Anchor Books.

Besharov, M L and Smith, W K (2014) Multiple institutional logics in organizations: explaining their varied nature and implications. Academy of Management Review, 39(3), 364-81.

Blazsin, H and Guldenmund, F (2015) The social construction of safety: comparing three realities. Safety Science, 71, 16-27.

Brousseau, E, Garrouste, P and Raynaud, E (2011) Institutional changes: Alternative theories and consequences for institutional design. Journal of Economic Behavior and Organization, 79(1), 3-19.

Chan, M (2011) Fatigue: the most critical accident risk in oil and gas construction. Construction Management and Economics, 29, 341-53.

Chan, P W (2013) Queer eye on a 'straight' life: deconstructing masculinities in construction. Construction Management and Economics, 31(8), 816-31.

Chi, C-F, Chang, T-C and Ting, H-I (2005) Accident patterns and prevention measures for fatal occupational falls in the construction industry. Applied Ergonomics, 36, 391-400.

Cooke, T and Lingard, H (2011) A retrospective analysis of work-related deaths in the Australian construction industry. In: Proceedings of the ARCOM Twenty-seventh Annual Conference, Egbu, C and Lou, E C W, Eds.), Reading UK: University of Reading, 279-88.

Czaniawska, B (2003) The styles and stylists of organization theory. In: Tsoukas, H and Knudsen, C (Eds.), The Oxford Handbook of Organization Theory: Meta-Theoretical Perspectives, pp. 237-61. Oxford: Oxford University Press.

Dainty, A R J, Bagilhole, B M and Neale, R H (2000) A grounded theory of women's career underachievement in large UK construction companies. Construction Management and Economics, 18(2), 239-50.

Dewey, J (1938) Logic: The Theory of Inquiry. New Tork: Holt, Rinehart and Winston.

DiMaggio, P (1994) Culture and economy. In: Smelser, N J and Swedberg, R (Eds.), The Handbook of Economic Sociology. Princeton, N. J.: Princeton University Press.

Durand, R, Szostak, B, Joursan, J and Thornton, P H (2013) Institutional logics as strategic resources, Institutional logics in action, Part A, pp. 165-201.

Fellows, R (2009) Advanced Research Methods in the Built Environment. Construction Management and Economics, 27(6), 605-9.

Fellows, R and Liu, A (2008) Research Methods for Construction (3rd ed.). Oxford: Wiley-Blackwell.

Friedland, R and Alford, R R (1991) Bringing society back in: symbols, practices, and institutional contradictions. In: Powell, W W and Dimaggio, P J (Eds.), The New Institutionalism in Organizational Analysis, pp. 232-63. Chicago: The University of Chicago Press.

Gibb, A, Lingard, H, Behm, M and Cooke, T (2014) Construction accident causality: learning from different countries and differing consequences. Construction Management and Economics, 32(5), 446-59.

Gibb, A, Haslam, R, Gyi, D, Hide, S and Duff, R (2006) What causes accidents? Civil Engineering, 159(November 2006), 47-50.

Glaser, B G (1978) Theoretical Sensitivity. Mill Valley, Calif.: Sociology Press

Glaser, B G (1992) Basics of Grounded Theory Analysis. Mill Valley, Calif.: Sociology Press

Glaser, B G (2001) The Grounded Theory Perspective: Conceptualization Contrasted with Description. Mill Valley, Calif.: Sociology Press

Glaser, B G (2003) The Grounded Theory Perspective II: Description's Remodeling of Grouneded Theory Methodology. Mill Valley, Calif.: Sociology Press

Glaser, B G (2005) The Grounded Theory Perspective III: Theoretical Coding. Mill Valley, Calif.: Sociology Press

Glaser, B G and Strauss, A L (1967) The Discovery of Grounded Theory: Strategies for Qualitative Research. London: Weidenfeld and Nicolson.

Goodman, N (1978) Ways of Worldmaking. Indianapolis: Hackett.

Greenwood, R, Díaz, A M, Li, S X and Lorente, J C (2010) The multiplicity of institutional logics and the heterogeneity of organizational responses. Organization Sciece, 21(2), 521-39.

Griffin, C and BengrY-Howell, A (2007) Ethnography. In: Willig, C and Stainton-Rogers, W (Eds.), The SAGE Handbook of Qualitative Research in Psychology, pp. 15-31. LA: Sage.

Hale, A R (2009) Why safety performance indicators? Safety Science, 47, 479-80. 
Haslam, R A, Hide, S A, Gibb, A G F and Gyi, D E (2003) Causual factors in construction accidents. UK: Health and Safety Executive (Research Report 156).

Haslam, R A, Hide, S A, Gibb, A G F, Gyi, D E, Pavitt, T, Atkinson, S and Duff, A R (2005) Contributing factors in construction accidents. Applied Ergonomics, 36, 401-15.

Helander, M (1980) Safety challenge in the construction industry. Journal of Occupational Accidents, 2, 257-63.

Hinze, J, Thurman, S and Wehle, A (2013) Leading indicators of construction safety performance. Safety Science, 51, 23-8.

Hollnagel, E (2008) Investigation as an impediment to learning. In: Hollnagel, E, Nemeth, C P and Dekker, S (Eds.), Resilience Engineering Perspectives, Volume 1: Remaining Sensitive to the Possibility of Failure, pp. 259-68. Aldershot, UK: Ashgate.

Jia, A Y, Rowlinson, S and Ciccarelli, M (2016) Climatic and psychosocial risks of heat illness incidents on construction site. Applied Ergonomics, 53, 25-35.

$\mathrm{Ju}, \mathrm{C}$ and Rowlinson, S (2014) Institutional determinants of construction safety management strategies of contractors in Hong Kong. Construction Management and Economics, 32(7-8), 725-36.

Kerlinger, F N (1986) Foundations of Behavioral Research. 3rd ed. New York: Holt Rinehart \& Winston.

Kirk, J and Miller, M L (1986) Reliability and Validity in Qualitative Research. London: Sage.

Kuhn, T S (2002 [1962]) The Structure of Scientific Revolutions (4th ed.). Chicago: University of Chicago Press

Kvan, T and Gao, S (2004) Problem framing in multiple settings. International Journal of Architectural Computing, 2(4), 444-60.

Langford, D and Hughes, W, (Eds.) (2009) Building a Discipline: The Story of Construction Management. Reading, UK: ARCOM.

Leithead, C S and Lind, A R (1964) Heat Stress and Heat Disorders. London: Cassell.

Lincoln, Y S and Guba, E G (1985) Naturalistic inquiry. Beverly Hills: Sage Pubns.

Lingard, H and Rowlinson, S (1998) Behaviour-based safety management in Hong Kong's construction industry: the results of a field study. Construction Management and Economics, 16, 481-8.

Liu, A M M and Fellows, R (2001) An Eastern perspective on partnering. Engineering, Construction and Architectural Management, 8(1), 9-19.

Liu, J H, Li, M-C and Yue, X (2010) Chinese social identify and inter-group relations: the influence of benevolent authority. In: Bond, M H (Ed.), The Oxford handbook of Chinese Psychology. Oxford: Oxford University Press.

Loosemore, M (1998) A grounded theory of construction crisis management. Construction Management and Economics, 17(1), 9-19.

Loosemore, M and Phua, F (2010) Responsible Corporate Strategy in Construction and Engineering: Doing the Right Thing? London and New York: Routledge.

Loosemore, M, Powell, A, Blaxland, M, Galea, N, Dainty, A and Chappell, L (2015) Rapid ethnography in construction gender research. In: Raidén, A and Aboagye-Nimo, E (Eds.), Procs 31st Annual ARCOM Conference, pp. 127180. 7-9 September 2015, Lincoln, UK: Association of Researchers in Construction Management.

Lundberg, J, Rollenhagen, C and Hollnagel, E (2009) What-You-Look-For-Is-What-You-Find-The consequences of underlying accident models in eight accident investigation manuals. Safety Science, 47(10), 1297-311.

Malchaire, J, Piette, A, Kampmann, B, Mehnert, P, Gebhardt, H, Havenith, G, Hartog, E d, Holmer, I, Parsons, K, Alfano, G and Griefahn, B (2001) Development and validation of the Predicted Heat Strain model. Annals of Occupational Hygiene, 45(2), 123-35.

Marshall, N and Bresnen, M (2013) Where's the action? Challenges of ethnographic research in construction. In: Pink, S, Tutt, D and Dainty, A (Eds.), Ethnographic Research in the Construction Industry, pp. 108-24. New York: Routledge.

Miesing, P and Preble, J F (1985) A comparison of five business philosophies. Journal of Business Ethics, 4(6), 465-76.

Mohammad, M Z and Hadikusumo, B H W (2015) A model of integrated multilevel safety intervention practices in construction industry. In: Behm, M and Mcaleenan, C (Eds.), Proceedings of CIB W099 Benefitting Workers and Society through Inherently Safe(r) Construction Belfast, Northern Ireland, 10-11 September 2015, pp. 49-61.

Moore, P (2013) 'On the tools' : the physical work of building and epistemology in construction fieldwork. In: Pink, S, Tutt, D and Dainty, A (Eds.), Ethnographic Research in the Construction Industry, pp. 58-72. New York: Routledge.

Mullan, B, Smith, L, Sainsbury, K, Allom, V, Paterson, H and Lopez, A-L (2015) Active behaviour change safety interventions in the construction industry: A systematic review. Safety Science, 79, 139-48.

Murray, M and Langford, D (2004) Architect's Handbook of Construction Project Management. London: RIBA Entreprise.

North, D (1990) Institutions, Institutional Change and Economic Performance. Cambridge and New York: Cambridge University Press.

Ostrom, E (1990) Governing the Commons: The Evolution of Institutions for Collective Action. Cambridge, UK.: Cambridge University Press.

Ostrom, E (2005) Understanding Institutional Diversity. Princeton: Princeton University Press.

Ostrom, E, Gardner, R and Walker, J (1994) Rules, Games, and Common-Pool Resources. Ann Arbor: University of Michigan Press.

Parsons, K (2014) Human Thermal Environments: The Effects of Hot, Moderate, and Cold Environments on Human Health, Comfort, and Performance (3rd ed.). London: CRC Press.

Pettit, P (2008) Three conceptions of democratic control. Constellations, 15(1), 46-55.

Piaget, J (1955) The Language and Thought of the Child. New York: Meridian Books.

Pink, S, Tutt, D, Dainty, A and Gibb, A (2010) Ethnographic methodologies for construction research: knowing, practice and interventions. Building Research \& Information, 38(6), 647-59.

Powell, W W and DiMaggio, P J (1991) The New Institutionalism in Organizational Analysis. Chicago: The University of Chicago Press. 
Raiffa, H (1968) Decision Analysis. Reading, MA: Addison-Wesley.

Roland, G (2004) Understanding institutional change: Fast-moving and slow-moving institutions. Studies in Comparative International Development, 38(4), 109-31.

Rowlinson, S and Jia, A Y (2014) Application of the Predicted Heat Strain Model in development of localized, thresholdbased heat stress management guidelines for the construction industry Annals of Occupational Hygiene, 58(3), 326-39, 10.1093/annhyg/met070.

Rowlinson, S and Jia, A Y (2015) Construction accident causality: an Institutional analysis of heat illness incidents on site. Safety Science, 78, 179-89.

Rowlinson, S, Jia, A Y, Li, B and Ju, C C (2014) Management of climatic heat stress risk in construction: a review of practices, methodologies, and future research. Accident Analysis and Prevention, 66, 187-98.

Schön, D (1984) Problems, frames and perspectives on designing. Design Studies, 5(3), 132-6.

Schön, D (1988) Designing: rules, types and worlds. Design Studies, 9(3), 181-90.

Schön, D A (1983) The Reflective Practitioner: How Professionals Think in Action. New York: Basic Books.

Schön, D A (1987) Educating the Reflective Practitioner. Hoboken, NJ.: Jossey-Bass.

Seymour, D, Crook, D and Rooke, J (1997) The role of theory in consruction management: a call for debate. Construction Management and Economics, 15, 117-9.

Sherratt, F, Farrell, P and Noble, R (2013) UK construction site safety: discourses of enforcement and engagement. Construction Management and Economics, 31(6), 623-35.

Shipton, C, Hughes, W and Tutt, D (2014) Change management in practice: an ethnographic study of changes to contract requirements on a hospitcal project. Construction Management and Economics, 32(7-8), 787-803.

Simon, H (1957) Administrative Behavior (2nd ed.). New York: The Free Press.

South China Morning Post (27 May 2014) Hong Kong facing shortage of 10,000 construction workers - and MTR is suffering. (reported by Phila Siu).

Strauss, A and Corbin, J (1990) Basics of Qualitative Research: Grounded Theory Procedures and Techniques. Newbury Park, Calif.: Sage Publications.

Thornton, P H (2001) Personal versus market logics of control: a historical contingent theory of the risk of acquisition. Organization Science, 12(3), 294-311.

Thornton, P H (2004) Markets from Culture: Institutional Logics and Organizational Decisions in Higher Education Publishing. Stanford, California: Stanford University Press.

Thornton, P H and Ocasio, W (1999) Institutional logics and the historical contingency of power in organizations: executive succession in the higher education publishing industry, 1958 - 1990. American Journal of Sociology, 105(3), 80143.

Thornton, P H and Ocasio, W (2008) Institutional logics. In: Greenwood, R, Oliver, C, Suddaby, R and Sahlin, K (Eds.), Handbook of Organizational Institutionalism, pp. 99-129. Thousand Oaks, CA: Sage.

Thornton, P H, Jones, C and Kury, K (2005) Institutional logics and institutional change in organizations: transformation in accounting, architecture, and publishing. Research in the Sociology of Organizations, 23, 125-70.

Thornton, P H, Ocasio, W and Lounsbury, M (2013) The Institutional Logics Perspective: A New Approach to Culture, Structure and Process. Oxford: Oxford University Press.

Turner, B S, Abercrombie, N and Hill, S (1986) Sovereign Individuals of Capitalism. New York: Routledge.

Tutt, D, Pink, S, Dainty, A R J and Gibb, A (2013a) Building networks to work: an ethnographic study of informal routes into the UK construction industry and pathways for migrant up-skilling. Construction Management and Economics, 31(10), 1025-37.

Tutt, D, Pink, S, Dainty, A R J and Gibb, A (2013b) 'In the air' and below the horizon: migrant workers in UK construction and the practice-based nature of learning and communicating OHS. Construction Management and Economics, 31(6), 515-27.

Weintraub, E R (2002) Neoclassical economics. In: Henderson, D R (Ed.), The Concise Encyclopedia of Economics. Monterey, California: Liberty Fund, Inc. 
Appendix 1. Details of samples

\begin{tabular}{|c|c|c|c|c|c|c|c|}
\hline \multirow[b]{2}{*}{ SN } & \multirow{2}{*}{$\begin{array}{l}\text { Site } \\
\text { code }\end{array}$} & \multirow{2}{*}{$\begin{array}{l}\text { Dates of study } \\
\text { (dates/month) }\end{array}$} & \multirow[b]{2}{*}{ Nature of project } & \multirow[b]{2}{*}{ Trades } & \multicolumn{3}{|c|}{ Data } \\
\hline & & & & & $\mathrm{P}$ & $\mathrm{W}$ & $\mathrm{M}$ \\
\hline \multicolumn{8}{|c|}{ Hong Kong study (2010) } \\
\hline 1 & EHCP & $19,26 / 8 ; 2,9 / 9$ & Building (public housing) & Plasterer; carpenter & 6 & 6 & 1 \\
\hline 2 & MTRP & 20,27/8; 3,10/9 & Civil (piling) & Piler & 6 & 6 & 1 \\
\hline 3 & EHCR & 24,31/8; 7,14,16/9 & Building (public housing) & Steel bender & 6 & 6 & \\
\hline 4 & MTRR & $1,8,15,29 / 9$ & Civil (piling) & Steel bender and fixer & 6 & 6 & \\
\hline 5 & HKHA & $6,13,27,28 / 9$ & $\begin{array}{l}\text { Footpath maintenance in public } \\
\text { housing village }\end{array}$ & Concretor & 6 & 6 & 1 \\
\hline \multicolumn{8}{|c|}{ Hong Kong study (2011) } \\
\hline 6 & HKUR & $24-25 / 3 ; 6-8 / 6$ & Building (university) & Rebar & 6 & 6 & 1 \\
\hline 7 & HKUC & 28-29/3; 6-8/6 & Building (university) & Carpenter (fender) & 6 & 6 & 1 \\
\hline 8 & HKUP & $31 / 3-2 / 4 ; 6-8 / 6$ & Building (university) & Plasterer & 6 & 6 & \\
\hline 9 & MTRL & $19-20 / 4 ; 13-14 / 6$ & Civil (levelling) & Leveller & 5 & 5 & 1 \\
\hline 10 & MTRT & $21,26 / 4 ; 13-14 / 6$ & Civil (tunnelling) & Miner, electrician & 6 & 6 & \\
\hline 11 & ICHK & $9,16,23,25 / 4$ & RMAA (school renovation) & $\begin{array}{l}\text { MEP, demolition worker, } \\
\text { plasterer, HAVC fitter, foreman }\end{array}$ & 12 & 12 & 1 \\
\hline 12 & XRL & $16-17 / 4$ & Civil (train station) & General workers & 8 & 8 & 2 \\
\hline 13 & ARQ & $24-25 / 6$ & Civil (quary) & $\begin{array}{l}\text { Leveler, shotfirer, driller, } \\
\text { operator, mechanics }\end{array}$ & 11 & 11 & 1 \\
\hline 14 & СРСТ & $27-28 / 6$ & Building (airport) & Rebar, carpenter & 10 & 10 & 3 \\
\hline 15 & LCKS & $29-30 / 6$ & Civil (highway) & rebar, rigger & 9 & 9 & 1 \\
\hline 16 & RDCK & $5-6 / 7$ & $\begin{array}{l}\text { Building (commercial } \\
\text { residential) }\end{array}$ & Rebar, plasterer, foreman & 12 & 11 & 3 \\
\hline 17 & CSP & 7-8/7 & Building (piling) & Rigger, plant operator & 12 & 12 & 3 \\
\hline 18 & HATSS & $11-12 / 7$ & $\begin{array}{l}\text { Civil (underground water } \\
\text { treatment facilities) }\end{array}$ & Miner, ganger, rigger & 9 & 9 & 2 \\
\hline 19 & TMRE & $15-16 / 7$ & Civil (highway) & Metal scaffolder, welder & 8 & 7 & 3 \\
\hline 20 & EXST & $19-20 / 7$ & Building (public housing) & Carpenter, rebar & 11 & 11 & 0 \\
\hline 21 & STFP & $21-22 / 7$ & Civil (foundation) & Rebar, welder, rigger & 12 & 9 & 3 \\
\hline 22 & LNTK & $26-27 / 7$ & Building (demolition) & Demolition, crane operator & 10 & 10 & 0 \\
\hline 23 & TSER & $3-4 / 8$ & Unit renovation (public housing) & Demolition, plasterer & 10 & 5 & 3 \\
\hline 24 & ASIL & 8-9/8 & Civil (foundation) & Driller & 10 & 9 & 0 \\
\hline 25 & MTRA & $5-6 / 8$ & Civil (tunnelling) & Rebar, carpenter, MEP & 4 & 3 & 0 \\
\hline 26 & YTSC & $15-16 / 8$ & Building (shopping mall) & HAVC fitter, foreman & 10 & 8 & 2 \\
\hline 27 & PTER & $18-19 / 8$ & Unit renovation (public housing) & Spalling, plasterer & 9 & 8 & 0 \\
\hline 28 & MTRO & $22-23 / 8$ & Civil (railway) & Carpenter, welder & 6 & 5 & 1 \\
\hline 29 & NLTH & $25-26 / 8$ & Building (hospital) & Rigger, scaffolder & 10 & 10 & 3 \\
\hline 30 & EKRR & $29-30 / 8$ & Maintenance (roadside pipeline) & Pipelayer & 10 & 7 & 2 \\
\hline 31 & KSWE & $1-2 / 9$ & Public housing maintenance & Spalling, BMW, plasterer & 5 & 5 & 3 \\
\hline 32 & MTRK & $5-6 / 9$ & Civil (tunnelling) & Miner, rigger & 5 & 5 & 3 \\
\hline 33 & SSWE & 8-9/9 & Unit renovation (public housing) & Plumber, joiner, plasterer & 6 & 6 & 3 \\
\hline 34 & MWEM & $15-16 / 9$ & $\begin{array}{l}\text { Electronic maintenance } \\
\text { (roadside) }\end{array}$ & Electronic technician & 4 & 4 & 0 \\
\hline \multicolumn{7}{|c|}{ Manager’s focus group/informal interview from industrial workshop and kick-off meetings } & 48 \\
\hline \multicolumn{8}{|c|}{ Chongqing study (2013) } \\
\hline 1 & VK01 & $24 / 4$ & Building (finishing) & Plasterer & 2 & 2 & 2 \\
\hline 2 & VK02 & $26-27 / 4$ & Building & Formworker, concretor & 4 & 4 & 7 \\
\hline
\end{tabular}

Abbreviations: P - sample of physiological record; W - worker's interview; M - manager's interview 
Appendix 2. Example of an authenticated case

\begin{tabular}{|c|c|c|c|c|c|}
\hline Case 13 & \multicolumn{2}{|c|}{ Items } & \multicolumn{3}{|r|}{ Data } \\
\hline \multicolumn{3}{|c|}{ Subject (code) } & \multicolumn{3}{|c|}{ CSP03 } \\
\hline \multirow{7}{*}{$\begin{array}{l}\text { Job } \\
\text { characteristi } \\
\text { cs }\end{array}$} & \multicolumn{2}{|l|}{ Trade } & \multicolumn{3}{|c|}{ Rigger (plant operator) } \\
\hline & \multicolumn{2}{|c|}{ Work experience } & \multicolumn{3}{|c|}{$1 \mathrm{yr}$} \\
\hline & \multicolumn{2}{|c|}{ Contractor } & \multicolumn{3}{|c|}{ A large contractor (anonymised) } \\
\hline & \multicolumn{2}{|c|}{ Project } & \multicolumn{3}{|c|}{ Foundation work of a Public Rental Housing } \\
\hline & \multicolumn{2}{|c|}{ Client } & \multicolumn{3}{|c|}{ Public sector (anaonymised) } \\
\hline & \multicolumn{2}{|c|}{ Location } & \multicolumn{3}{|c|}{ Sheng Shui } \\
\hline & \multicolumn{2}{|c|}{ Date, study } & \multicolumn{3}{|c|}{ 7-8 July 2011} \\
\hline \multirow{10}{*}{$\begin{array}{l}\text { Personal } \\
\text { infor }\end{array}$} & \multicolumn{2}{|c|}{ Age } & \multicolumn{3}{|c|}{37} \\
\hline & \multicolumn{2}{|l|}{ Sex } & \multicolumn{3}{|l|}{ M } \\
\hline & $B M I$ & & $27(1$ & $5 \mathrm{M} / 82$ & 2.7kg) overweight \\
\hline & Fitnes & & 119( & oor, 6) & \\
\hline & Blood & & Norn & , 5.3 & (reported to have taken sweet herbal tea at 11pm last night) \\
\hline & Blood & ssure & Norn & & \\
\hline & Health & & Smol & & \\
\hline & Sleep & lity & Day1 & Good; & Day2 - Poor \\
\hline & Body 1 & p. (ear) & $36.2^{\circ}$ & & \\
\hline & $H R_{0}$ & & $77 \mathrm{bp}$ & & \\
\hline RPE \& Activ & ties & Session & Met & RPE & Activities \\
\hline & & DAY 1: & & & \\
\hline & & 0911-0916 & 141 & & \\
\hline & & 0917-0925 & 121 & & Hammoring crrous \\
\hline & & 0926-0948 & 207 & 13 & Hammermg screws \\
\hline & & 0949-1019 & 179 & & \\
\hline & & 1020-1127 & 217 & & \\
\hline & & 1128-1218 & 154 & & Lunch \\
\hline & & 1219-1356 & 251 & & "The toughest time is after lunch, ....strongest sunlight. \\
\hline & & 1357-1405 & 174 & & Took breaks when it was too hot.” \\
\hline & & 1406-1414 & 238 & & \\
\hline & & $1415-1426$ & 176 & 15 & Hammering screws. I nad some neat exnaustion symptom \\
\hline & & 1427-1448 & 237 & & \\
\hline & & 1449-1538 & 180 & & \\
\hline & & 1539-1811 & 306 & & \\
\hline & & DAY 2: & & & \\
\hline & & 0931-0936 & 171 & & $\begin{array}{l}\text { "We were rushing the work yesterday. We worked until } \\
\text { 11pm, pouring concrete. I did not get a sleep until 2-3am }\end{array}$ \\
\hline & & 0937-1150 & 278 & 15 & $\begin{array}{l}\text { Once we start concrete pouring work, we have several } \\
\text { pumps rotate. We have such intensive work once or twice a } \\
\text { week." }\end{array}$ \\
\hline & & 1151-1211 & 151 & & \\
\hline & & 1212-1307 & 91 & & Lunch \\
\hline & & 1308-1432 & 231 & & Today is tougher. The weather is very hot and humid. The \\
\hline & & $1433-1438$ & 144 & & hardest time is between 1-2 pm, with the strongest \\
\hline & & 1439-1503 & 228 & & sunlight. I worked on hammering, rigging, drilling (on the \\
\hline & & 1504-1508 & 156 & & work platform over the high tower and climbed down for \\
\hline & & 1509-1709 & 244 & 17 & breaks). When I had work to do, I slowed down when \\
\hline & & 1701-1811 & 126 & & $\begin{array}{l}\text { necessary, took a rest at shaded pace, and had some water. } \\
\text { But when you drink too much water you feel thirsty } \\
\text { because of lack of salt. Today at } 2 \text { pm the hottest time I } \\
\text { had heat exhaustion. }\end{array}$ \\
\hline
\end{tabular}




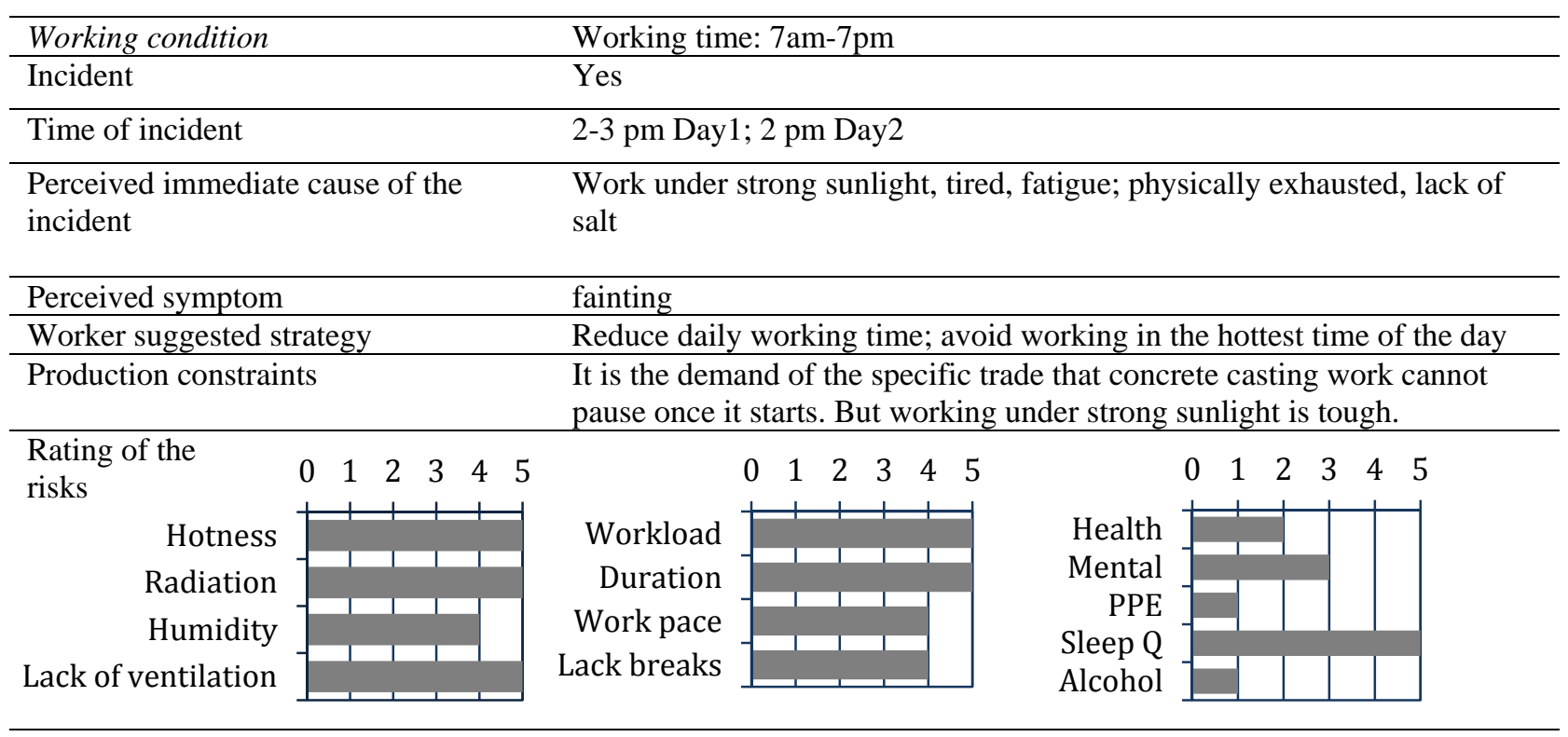

Ratings of the usefulness of interventions $\begin{array}{llllll}0 & 1 & 2 & 3 & 4 & 5\end{array}$

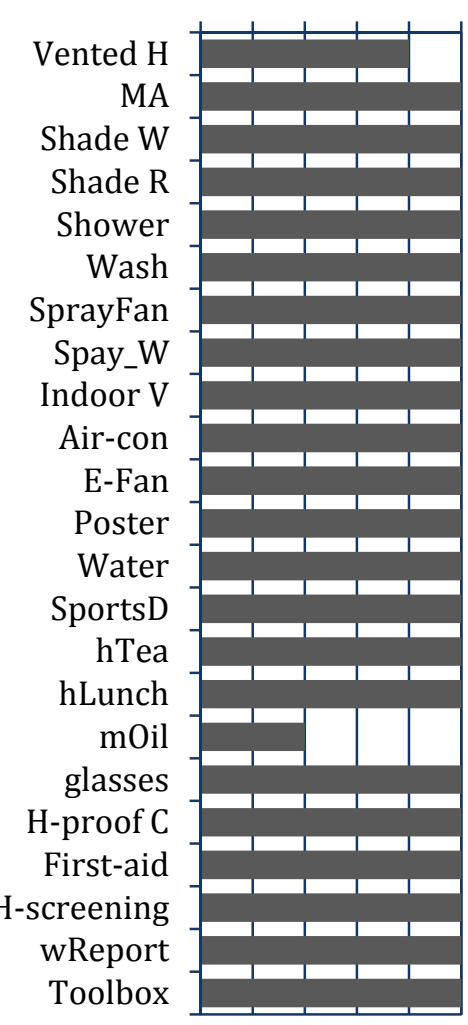

$\begin{array}{llllll}0 & 1 & 2 & 3 & 4 & 5\end{array}$

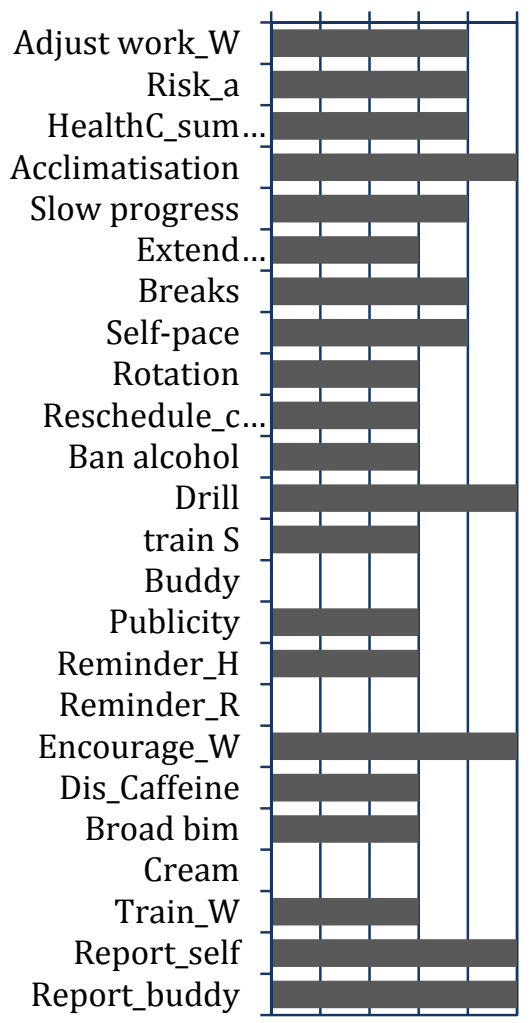




\title{
Appendix 2. Example of an authenticated case (continued)
}

\author{
Context for Case 12-18 CSP
}

\begin{tabular}{|c|c|c|}
\hline \multicolumn{2}{|c|}{ Items } & Interview notes \\
\hline \multirow[t]{7}{*}{ Project } & Site code & CSP \\
\hline & Project & Foundation for Public Rental Housing Development \\
\hline & Client & Public Sector (anonymised) \\
\hline & Contractor & A large contractor (anonymised) \\
\hline & Location & Sheng Shui \\
\hline & Date, study & 7-8 July 2011 \\
\hline & $\begin{array}{l}\text { Site } \\
\text { description }\end{array}$ & $\begin{array}{l}\text { Major risks in this project are working on high, object falling from high, as } \\
\text { rigging is the major work at this stage; the depth of the foundation is 50-60 M. } \\
\text { The site has sun umbrellas for shades. Workers use salted fruits to accompany } \\
\text { drinking water to make their own sports drink. 1-2 bottles of herbal tea were } \\
\text { provided to workers once a week. Riggers were provided with sun glasses, } \\
\text { however, was complained by workers as "no string, not usable.” The site } \\
\text { planned to report weather on site. Health check is done at induction, including } \\
\text { body temperature and blood pressure. }\end{array}$ \\
\hline \multirow{13}{*}{\multicolumn{2}{|c|}{$\begin{array}{l}\text { Ineffective interventions } \\
\text { and interpretation }\end{array}$}} & $\begin{array}{l}\text { Workers have to drink sweet soda water with high sugar to feel recharged of } \\
\text { energy. [conflicting health effect] }\end{array}$ \\
\hline & & Training is provided to supervisor in their induction session. \\
\hline & & $\begin{array}{l}\text { Buddy system: nowadays all works are assigned to a group. There is no } \\
\text { individual work. }\end{array}$ \\
\hline & & $\begin{array}{l}\text { Emergency drills are only performed on Fire alarm, flood and typhoon, not on } \\
\text { heat stroke. }\end{array}$ \\
\hline & & $\begin{array}{l}\text { "In terms of alcohol, rebar workers do drink on site. This is their habit. Other } \\
\text { trades do not have this habit." }\end{array}$ \\
\hline & & $\begin{array}{l}\text { Rotation of duties is not practised, but even it is practised it was not for } \\
\text { avoiding hot period but for speeding up the progress and keep the project } \\
\text { running } 24 \text { hours a day. }\end{array}$ \\
\hline & & $\begin{array}{l}\text { During the period of pouring concrete, all the job related measures cannot be } \\
\text { practiced except self-pacing. - In fact the concereting work is not self-paced } \\
\text { but paced by the pumping truck. }\end{array}$ \\
\hline & & $\begin{array}{l}\text { Nepalese workers: we have communication problem. If we have two of them, } \\
\text { they are diligent. But we don't hire too many of them, because once three or } \\
\text { more of them work together, they do not follow instruction. We can hire more } \\
\text { in bigger site so that they can be dispersed in different locations of the site. }\end{array}$ \\
\hline & & Heat stress prevention is talked during morning brief, as well as in poster. \\
\hline & & $\begin{array}{l}\text { Two trades do not use reflective vest: welders and rebar workers. Welding } \\
\text { work has the risk of burning the vest. Rebar has the risk of being hooked by } \\
\text { crawling materials. }\end{array}$ \\
\hline & & $\begin{array}{l}\text { Vented helmet is not very effective. The work has many chances to have water. } \\
\text { Holes on the helmet are not good for water proof. [conflicting effect] }\end{array}$ \\
\hline & & Broad brim helmet is not good for eye sight; not good for body balance. \\
\hline & & Instead of using sun cream, we encourage workers to dress long sleeve clothes. \\
\hline \multicolumn{2}{|c|}{$\begin{array}{l}\text { Management strategy } \\
\text { for HS }\end{array}$} & $\begin{array}{l}\text { As soon as one feels discomfort, go and find a cool place to take rest until } \\
\text { recovery. }\end{array}$ \\
\hline
\end{tabular}




\section{Appendix 2. Example of an authenticated case (continued)}

Managers on this site: R063

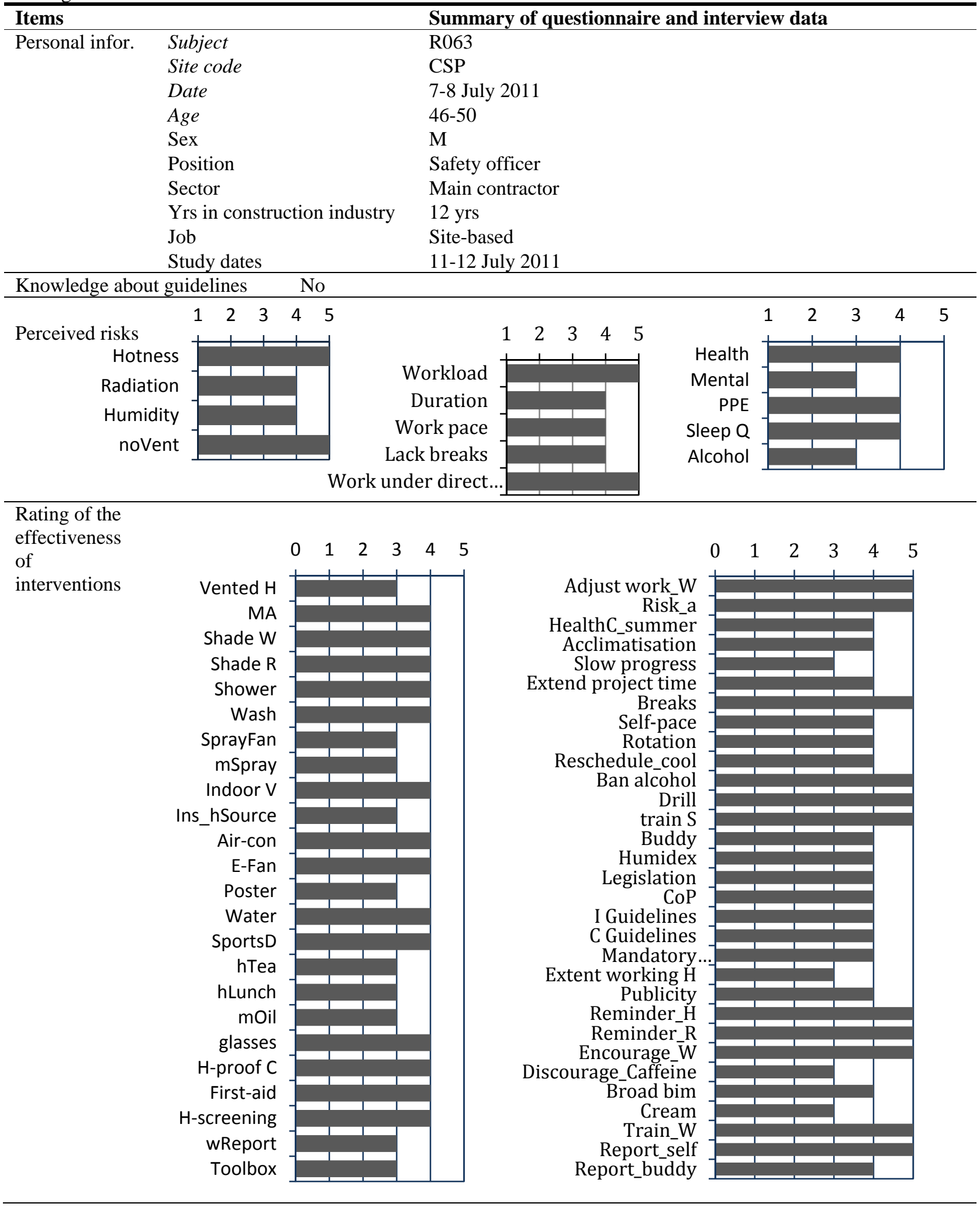




\section{Appendix 2. Example of an authenticated case (continued)}

R064 manager's questionnaire summary

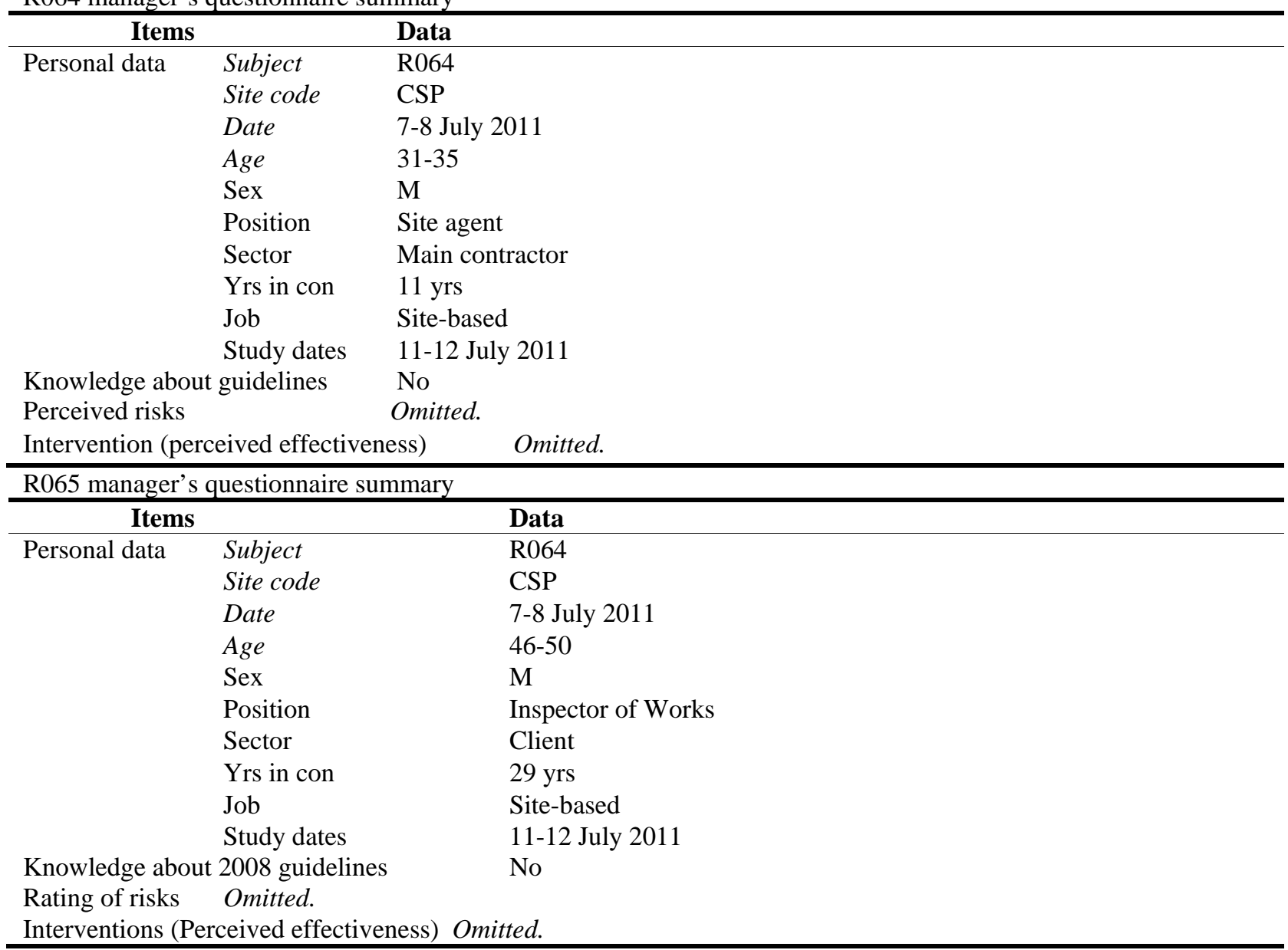

Field notes/Memo

1) In administering the questionnaires I have found the 2008 Guidelines are completely out of context. Through the site study we have turned the checklist/questionnaire into tools for interviews and focus groups.

2) Exceptions during the site study:

- A very experienced rebar worker gave us invaluable insights and detailed comments. But at the end of the study he stole his health record, which a week later was returned to us through his manager. I recalled that at the beginning he did ask for a copy of his health check result to show to his doctor. We need to be more attentive to their request.

- A crane operator claimed he had heat stress at 2 p.m. of the day, and he deliberately worked himself into heat stress while wearing the heart rate monitor in order to produce us some real data. We were very moved and tried to take care of him. His fellow workers were laughing. But when we checked back the data we found he had taken off the monitor at $11 \mathrm{a} . \mathrm{m}$. The data will be further triangulated with the environmental heat stress data.

- A female worker said she had skin allergy to the sensor of heart rate monitor. I told her then she didn't have to wear the heart rate monitor. But she worried about the \$150 Voucher and insisted to wear it. At the end of the day she brought back the monitor and claimed she wore it all the day. But we found in the computer that she actually took it off in one hour. The next day she came back enthusiastically and asked to wear the monitor again. I said "You don't have to wear it because of your allergy. Just complete the questionnaire and collect the Voucher." She was very much relieved and returned to us a well-answered questionnaire. I gave her the $\$ 150$ Voucher.

3) In fact our data collection itself has become a most effective intervention. Our enquiries made the managers try to perform, and they ask how other companies are managing heat stress on site. Our conversation with workers gave them a voice, and indeed they gave surprisingly wise insights. In participating the study, the sites provided a conference room for twelve workers and one manager to sit down together over four sessions. While waiting for health check they discussed and laughed with each other. This obviously changed the site culture, helped building trust between workers and their employers. 


\section{Appendix 3. Coding examples}

Examples of open coding

\begin{tabular}{|c|c|c|}
\hline \multirow{2}{*}{$\begin{array}{l}\text { Subject } \\
\text { NLTH03 }\end{array}$} & Interview notes & Code \\
\hline & $\begin{array}{l}\text { Nothing has improved. There are many }{ }^{1,2} \text { Nepalese workers doing } \\
\text { scaffolding work. They have the physical strength, so they have the priority } \\
\text { in employment. }{ }^{3} \text { Unless they cannot communicate, local workers can have } \\
\text { the job. It is a problem with company structure, the system, the problem with } \\
\text { the construction industry. }{ }^{4} \text { Every job needs a license. Some earned the } \\
\text { license through skilled work. Some have never tried the job but still got a } \\
\text { license. In fact the license doesn’t mean anything. }{ }^{5} \text { We know how to do the } \\
\text { job but can’t get a license. We are very pressured. I worked in the shipping } \\
\text { industry years ago. Weather in the sea is hotter than a construction site but } \\
\text { there has less heat stress, }{ }^{6} \text { because there you don't need to wear the safety } \\
\text { boots and the reflective vest, and }{ }^{7} \text { there is wind in the sea. Here you are } \\
\text { more vulnerable to heat stress. } \\
\text { But no problem. } \\
\text { years in Hong Kong vory easy for us to find a job in the recent six or seven } \\
\text { work environment we just find another job in another project. }\end{array}$ & $\begin{array}{l}{ }^{1} \text { Ethnicity } \\
{ }^{2} \text { Employment opportunity } \\
\text { (market) } \\
{ }^{3} \text { Communication (language) } \\
{ }^{4} \text { Industry level - licensing } \\
\text { system } \\
{ }^{5} \text { Psychological stress (sense } \\
\text { of unfairness) } \\
{ }^{6} \text { PPEs as heat risks } \\
{ }^{7} \text { Wind } \\
{ }^{8} \text { Market } \\
{ }^{9} \text { Worker mobility } \\
8,9 \text { Incentive for company to } \\
\text { improve OHS }\end{array}$ \\
\hline CSP04 & $\begin{array}{l}\text { I was working }{ }^{1} \text { on a jetty at }{ }^{2} \text { Tuen Mun river front. I was }{ }^{3} \text { setting the } \\
\text { electrical wires. It was }{ }^{4} \text { over } 30 \text { degree C. I worked }{ }^{5}{ }^{\text {in the electrical wire }} \\
\text { trench. It was }{ }^{6} \text { stuffy. I felt }{ }^{7} \text { dizzy and }{ }^{8} \text { my hand cramped. }{ }^{9} \text { The time was } \\
\text { around } 2 \text { P.M. }\end{array}$ & $\begin{array}{l}{ }^{1} \text { Workplace }{ }^{2} \text { Location } \\
{ }^{3} \text { Work activity } \\
{ }^{4} \text { Temperature }{ }^{5} \text { Workplace } \\
\text { (semi-confined space) } \\
{ }^{6} \text { Ventilation }{ }^{7,8} \text { Symptom } \\
{ }^{9} \text { Time of incident }\end{array}$ \\
\hline
\end{tabular}

Example of theoretical coding

Model (Case 25)

07-Jul-2013

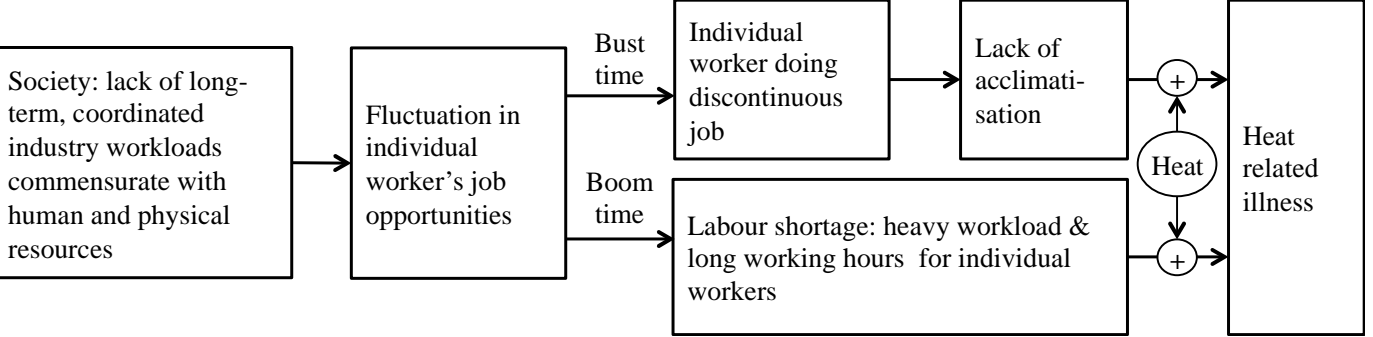

Industry: lack of long-term,

coordinated

Model (Case 25,31,32)

industry workloads

23-Aug-2013

commensurate with

human and physical resources

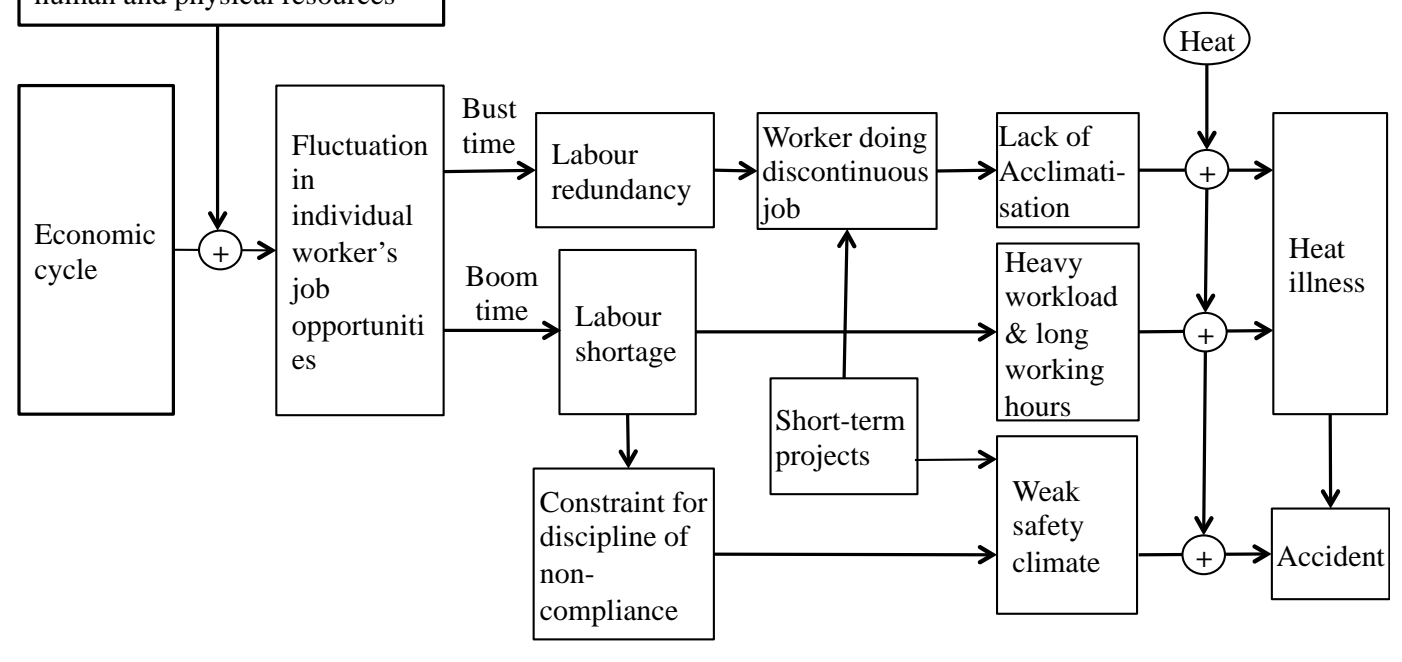

